\title{
Derivation of the reduced reaction mechanisms of ozone depletion events in the Arctic spring by using concentration sensitivity analysis and principal component analysis
}

\author{
Le Cao ${ }^{1}$, Chenggang Wang ${ }^{1}$, Mao Mao $^{1}$, Holger Grosshans ${ }^{2}$, and Nianwen Cao ${ }^{1}$ \\ ${ }^{1}$ Key Laboratory for Aerosol-Cloud-Precipitation of China Meteorological Administration, \\ Nanjing University of Information Science and Technology, Nanjing, China \\ ${ }^{2}$ Institute of Mechanics, Materials and Civil Engineering, Université catholique de Louvain, Louvain-la-Neuve, Belgium \\ Correspondence to: Le Cao (le.cao@nuist.edu.cn)
}

Received: 13 July 2016 - Published in Atmos. Chem. Phys. Discuss.: 29 August 2016

Revised: 25 October 2016 - Accepted: 5 November 2016 - Published: 1 December 2016

\begin{abstract}
The ozone depletion events (ODEs) in the springtime Arctic have been investigated since the 1980s. It is found that the depletion of ozone is highly associated with an auto-catalytic reaction cycle, which involves mostly the bromine-containing compounds. Moreover, bromide stored in various substrates in the Arctic such as the underlying surface covered by ice and snow can be also activated by the absorbed HOBr. Subsequently, this leads to an explosive increase of the bromine amount in the troposphere, which is called the "bromine explosion mechanism".

In the present study, a reaction scheme representing the chemistry of ozone depletion and halogen release is processed with two different mechanism reduction approaches, namely, the concentration sensitivity analysis and the principal component analysis. In the concentration sensitivity analysis, the interdependence of the mixing ratios of ozone and principal bromine species on the rate of each reaction in the ODE mechanism is identified. Furthermore, the most influential reactions in different time periods of ODEs are also revealed. By removing 11 reactions with the maximum absolute values of sensitivities lower than $10 \%$, a reduced reaction mechanism of ODEs is derived. The onsets of each time period of ODEs in simulations using the original reaction mechanism and the reduced reaction mechanism are identical while the maximum deviation of the mixing ratio of principal bromine species between different mechanisms is found to be less than $1 \%$.
\end{abstract}

By performing the principal component analysis on an array of the sensitivity matrices, the dependence of a par- ticular species concentration on a combination of the reaction rates in the mechanism is revealed. Redundant reactions are indicated by principal components corresponding to small eigenvalues and insignificant elements in principal components with large eigenvalues. Through this investigation, aside from the 11 reactions identified as unimportant in the concentration sensitivity analysis, additionally nine reactions were indicated to contribute only little to the total response of the system. Thus, they can be eliminated from the original reaction scheme. The results computed by applying the reduced reaction mechanism derived after the principal component analysis agree well with those by using the original reaction scheme. The maximum deviation of the mixing ratio of principal bromine species is found to be less than $10 \%$, which is guaranteed by the selection criterion adopted in the simplification process. Moreover, it is shown in the principal component analysis that $\mathrm{O}\left({ }^{1} \mathrm{D}\right)$ in the mechanism of ODEs is in quasi-steady state, which enables a following simplification of the reduced reaction mechanism obtained in the present study.

\section{Introduction}

Since the first discovery by Oltmans (1981) in observations conducted at Barrow, Alaska, in 1977, the ozone depletion events (ODEs) in polar spring have attracted great attention. Oltmans (1981) found that the surface ozone mixing ratio in Barrow dropped from a background value $(\sim 40 \mathrm{ppb}$, 
$\mathrm{ppb}=$ parts per billion) to a level lower than $1 \mathrm{ppb}$ within a couple of days. In a following measurement performed at Alert, Canada, not only the occurrence of the ozone depletion but also a negative correlation between the ozone mixing ratio and the concentration of filterable bromine (f-Br) was confirmed (Bottenheim et al., 1986; Barrie et al., 1988). Since then, ODEs and the associated bromine enhancement have been reported from various observation sites in polar regions (Kreher et al., 1997; Frieß et al., 2004; Jones et al., 2006, 2009, 2010; Wagner et al., 2007; Helmig et al., 2007, 2012; Halfacre et al., 2014).

Although, the concentration increase of the brominated species was found during ODEs, the mechanism responsible for the destruction of ozone with the involvement of bromine in the troposphere of the Arctic remained a matter of debate until the role of bromine monoxide $(\mathrm{BrO})$ was uncovered by Hausmann and Platt (1994). They suggested that the bromine species participate in an auto-catalytic reaction cycle (R1), namely,

$$
\begin{array}{ll}
2\left(\mathrm{Br}+\mathrm{O}_{3}\right. & \left.\rightarrow \mathrm{BrO}+\mathrm{O}_{2}\right) \\
\mathrm{BrO}+\mathrm{BrO} & \rightarrow \mathrm{Br}_{2}(\text { or } 2 \mathrm{Br})+\mathrm{O}_{2} \\
\mathrm{Br}_{2}+h v & \rightarrow 2 \mathrm{Br} \\
\hline \text { Net: } 2 \mathrm{O}_{3}+h v & \rightarrow 3 \mathrm{O}_{2}
\end{array}
$$

through which the ozone in the boundary layer is consumed without any loss of bromine. In the reaction sequence (R1), $\mathrm{BrO}$ participates in self-reactions through which $\mathrm{Br}$ atoms are formed. Since the reaction between ozone and $\mathrm{Br}$ is rapid, ozone in the boundary layer is continuously consumed in the presence of sunlight via the reaction sequence (R1). However, the reaction cycle (R1) is unable to explain the fast enhancement of bromine in the ambient air. Therefore, another reaction cycle (R2) is proposed as follows:

$$
\begin{array}{ll}
\mathrm{Br}+\mathrm{O}_{3} & \rightarrow \mathrm{BrO}+\mathrm{O}_{2} \\
\mathrm{BrO}+\mathrm{HO}_{2} & \rightarrow \mathrm{HOBr}+\mathrm{O}_{2} \\
\mathrm{HOBr}+\mathrm{H}^{+}+\mathrm{Br}^{-} & \rightarrow \mathrm{Br}_{2}+\mathrm{H}_{2} \mathrm{O} \\
\mathrm{Br} 2+h v & \rightarrow 2 \mathrm{Br} \\
\hline \mathrm{Net}: \mathrm{O}_{3}+\mathrm{HO}_{2}+\mathrm{H}^{+}+\mathrm{Br}^{-}+h v & \stackrel{\mathrm{mp}}{\rightarrow} 2 \mathrm{O}_{2}+\mathrm{Br}+\mathrm{H}_{2} \mathrm{O}
\end{array}
$$

In sequence (R2), the $\mathrm{HOBr}$, which is formed through the oxidation of $\mathrm{BrO}$, is capable of activating bromide ions stored in various polar substrates such as the suspended aerosols and ice-/snow-covered surfaces. As a result, the bromine amount in the ambient air rises up explosively. This reaction sequence is thus named as "bromine explosion mechanism" (Platt and Janssen, 1995; Platt and Lehrer, 1997; Wennberg, 1999). A detailed review of the auto-catalytic reaction cycles of ODEs and the bromine explosion mechanism is given by Platt and Hönninger (2003), Simpson et al. (2007), and Abbatt et al. (2012).

Since the 1990s, a large amount of numerical studies on the ozone depletion and halogen release in polar spring have been conducted. At first, zero-dimensional approaches (also termed "box models") were employed. Therein, a uniform distribution of the chemical species within the boundary layer was assumed. By using such a model, McConnell et al. (1992) suggested that the heterogeneous reactions that release $\mathrm{Br}^{-}$from the snowpack to the atmosphere are critical for sustaining high levels of $\mathrm{BrO}$ and $\mathrm{Br}$ in the ambient air. Moreover, Fan and Jacob (1992) showed that the release of $\mathrm{Br}_{2}$ from the suspended aerosols is essential for the occurrence of ODEs, whereas Tang and McConnell (1996) and Michalowski et al. (2000) proposed the snowpack above the sea ice surface as a bromine source. The aerosol particles were also included as a source in the photochemical box model MOCCA (Model Of Chemistry in Clouds and Aerosols) by Sander and Crutzen (1996). By adapting MOCCA to polar conditions (Sander et al., 1997), it was found that the rates of reactions between $\mathrm{Br}$ and $\mathrm{C}_{2} \mathrm{H}_{2}$ or $\mathrm{C}_{2} \mathrm{H}_{4}$ are critical for the ozone budget in the troposphere. Later on, the box model MECCA (Module Efficiently Calculating the Chemistry of the Atmosphere; Sander et al., 2005, 2006) revealed that the precipitation of $\mathrm{CaCO}_{3}$ from the freezing sea water reduces its buffering ability, which facilitates the acid-catalyzed activation process, as long as the mechanism of evapoconcentration during the formation of aerosol particles is considered (Sander and Morin, 2010). Finally, the authors of this paper (Cao et al., 2014, 2016a) revealed a series of reactions and several initial atmospheric constituents that determine the occurrence of ODEs by performing a concentration sensitivity analysis with the box model KINAL (Turányi, 1990a).

The one-dimensional (1-D) model studies of ODEs started with Lehrer et al. (2004), who parameterized the vertical distribution of the turbulent diffusivity as a linear function of height. They identified the fresh sea ice surface to be the primary bromine source. Saiz-Lopez et al. (2008) developed another 1-D chemical transport model and found that an initial $\mathrm{Br}_{2}$ flux from the snowpack is required for keeping the model simulations in accordance with measurements. Moreover, the 1-D Lagrangian-mode boundary layer model MISTRA (MIcrophysical STRAtus) (Bott et al., 1996; Bott, 1997, 2000) was modified by Piot and von Glasow (2008) to reproduce Arctic conditions. They found that the recycling process on snow is responsible for the existence of high-level bromine observed in the polar boundary layer. Piot and von Glasow (2009) also discovered that the elevation of $\mathrm{HCHO}$ and $\mathrm{Cl}_{2}$ fluxes leads to a bromine speciation shift from $\mathrm{Br} / \mathrm{BrO}$ to $\mathrm{HOBr} / \mathrm{HBr}$. This accelerates the deposition of bromine on snow and, consequently, slows down ODEs. Noteworthy is also the 1-D model PHANTAS (PHotochemistry ANd Transport between Air and Snowpack) by Toyota et al. (2014). They found that in the top layers of the snowpack, the release of $\mathrm{Br}_{2}$ is dominantly driven by the bromine explosion mechanism. Furthermore, in deeper layers of snowpack, both the aqueous radical chemistry and the bromine explosion mechanism contribute substantially to the bromine evasion to the boundary layer. Recently, Cao et al. (2016b) added a module 
representing the vertical mass transfer between layers with different heights to KINAL, and referred to the new model as KINAL-T. Thereby, the influences caused by the change of the boundary layer height on the occurrence and termination of ODEs were studied.

The 3-D model studies on the tropospheric ODEs during polar spring started with Zeng et al. (2003). They suggested, using their regional chemistry transport model, that ODEs persist widespread in a large scale. Afterwards, Yang et al. (2010) added blowing snow as an additional bromine source to the global 3-D tropospheric model p-TOMCAT and found its importance for the bromine explosion. A major advancement of the 3-D models was made by Zhao et al. (2008). They used a global 3-D chemistry and transport model GEM$\mathrm{AQ} /$ Arctic to investigate the spatial structure and time series of ozone and $\mathrm{BrO}$ in the boundary layer during the Arctic springs of the years 2000 and 2001. The chemistry module MECCA described above was also implemented in GEM-AQ/Arctic, replacing the original chemistry module and solver. It was shown that not only the halogen chemistry but also the air temperature, atmospheric circulation, and long-range transport of pollutants make great contributions to the springtime ozone depletion in the Arctic. Another version of the 3-D model GEM-AQ incorporating the gasphase and heterogeneous bromine chemistry was employed by Toyota et al. (2011). They discovered the surface sources of bromine and $\mathrm{BrO}$ clouds that were observed in the boundary layer of the Arctic (Chance, 1998; Richter et al., 1998; Platt and Wagner, 1998; Wagner et al., 2001). An included source representing the oxidation of $\mathrm{Br}^{-}$by ozone at the snow-/ice-covered surfaces proved later to be the primary source of reactive bromine. In 2013, Cao and Gutheil coupled the 3-D model to a LES (large-eddy simulation) of the atmospheric flow using OpenFOAM in order to gain a better understanding of the turbulent mixing of ozone and brominerelated species in the boundary layer during ODEs. In their paper they also discussed the dependence of the ozone depletion rate on meteorological conditions such as the wind speed and the boundary layer stability.

The above-discussed theoretical studies revealed that ODEs are influenced by the joint effect of horizontal advection, vertical convection, and local chemistry. The potential to provide the information, which may enable investigators to fully understand the underlying physicochemical processes, is offered by the numerical simulation of ODEs of high dimensions with the incorporation of the halogen chemistry. However, the possibility of conducting highdimensional computations of ODEs is usually limited by the effort to calculate the chemical production and destruction source terms in the governing equations. If a complex reaction mechanism is adopted in these kinds of simulations, the execution time for the estimation of chemical source terms can exceed the one for solving transport equations by 1 order of magnitude.
Commonly, a one-step global reaction is adopted in 2-D or 3-D simulations of the atmospheric chemistry that leads to affordable computing times (Warnatz, 1992). However, the coefficients used in the one-step global reaction approach are usually empirical, which cannot be estimated without the aid of experimental studies. An alternative treatment of the chemistry in numerical studies is to choose a couple of elementary reactions that are able to describe the important features of the reaction system. However, the selection of elementary reactions needs special attention. If the treatment of the chemistry in the computation is too rough and arbitrary, the estimation of the chemical production and consumption would be inaccurate and, consequently, the simulation results may be far from reality. Thus, an appropriate reduced reaction mechanism is required so that the major properties of the original complex reaction mechanism are maintained. Moreover, the size of the reduced reaction mechanism should be small to enable the efficient computation of high-dimensional equations.

Previously, various approaches have been proposed to simplify a complex reaction mechanism while the major properties of the original reaction mechanism are maintained. The first type of the methods is represented by the rate spectrum analysis of the reaction scheme (Turányi et al., 1989). Therein, the rates of competing reactions are compared. However, this method is inapplicable for a very complex chemical system in which the influence of each reaction differs significantly on certain kinetic features of the system. The second type of methods is given by the grouping of the reactions into several categories (Edelson and Allara, 1980). The reaction that makes negligible contribution to the flux within its category is considered to be unimportant and, thus, can be eliminated from the reaction scheme. However, the grouping procedure of the reactions depends strongly on the experience of the investigator, which brings some arbitrariness to the application of this method. Moreover, the kinetic information inherent in the reaction mechanism may be lost if reactions belonging to a certain chemical kinetic structure are grouped separately. The third type of method is based on the analysis of the production rate of free radicals (Lifshitz and Frenklach, 1975). Reactions that make small contributions to the production or destruction of free radicals are omitted. The fourth approach for obtaining the reduced mechanism is referred to as rate-of-production analysis or reaction-path analysis (Glarborg et al., 1986). Herein, the individual contribution of each reaction to the overall production rate of selected chemical species is estimated. Moreover, the major formation pathway of the chemical species is identified.

A more complicated method, which is able to extract the inherent information from the kinetic mechanism and discriminate reactions from complex chemical reaction schemes, is the sensitivity analysis (Rabitz et al., 1983; Turányi, 1990b). Sensitivity analysis is a routinely used technique, which reveals interdependence between the species 
concentrations and the change of reaction rates. Finally, it helps to reduce the size of the reaction mechanism. At present, the sensitivity analysis is often conducted in a "brute force" way (Dodge and Hecht, 1975; Valko and Vajda, 1984) by simply applying a perturbation of reaction rate coefficients by a fixed amount to see the corresponding deviations of particular species concentrations. This is time-consuming and provides only a limited accuracy. Since the 1980s, more systematic and economical approaches for the estimation of the sensitivities have been proposed. The most straightforward one is the concentration sensitivity analysis (Turányi, 1990b), which is capable of displaying the relative importance of an individual rate coefficient on a group of species concentrations and identifying the rate-determining steps in the reaction scheme. The concentration sensitivity analysis has also been used for screening reactions from a complicated reaction mechanism in various fields such as the investigation of combustion (Dougherty and Rabitz, 1980; Warnatz et al., 2001) and atmospheric chemistry (Turányi and Bérces, 1990).

However, the calculation of the concentration sensitivity coefficients depends on the time interval used in the model, which denotes that the concentration sensitivity is inherently time dependent. Thus, the accuracy of the sensitivity estimation is associated with the length of the time interval. Otherwise, the concentration sensitivity analysis only discovers the importance of an individual input parameter of the chemical kinetic system for several species concentrations while usually the concentrations are influenced by a group of parameters. Thus, another mechanism reduction approach, namely, the principal component analysis, is suggested (Vajda et al., 1985). The principal component analysis is performed based on the calculation of eigenvalues and eigenvectors of the matrix $\widetilde{\boldsymbol{S}} \mathrm{T} \widetilde{\boldsymbol{S}}$, wherein $\widetilde{\boldsymbol{S}}$ denotes an array of the relative concentration sensitivity matrices. Strongly interacting reactions, which significantly influence the concentration of particular species, are identified by principal components with large eigenvalues. Moreover, further mechanistic details of the chemical kinetic system, such as the species in quasisteady state, can also be provided by the principal component analysis.

Although the mechanism reduction techniques mentioned above have been applied in the investigation of various atmospheric phenomena, such as the chemistry in clouds (Pandis and Seinfeld, 1989), to date little effort has been given to the reduction of the reaction mechanism of ODEs using these techniques. Previous research by the authors (Cao and Gutheil, 2013; Cao et al., 2014) focused on this aspect to some extent. In these studies, relative concentration sensitivities of a reaction mechanism of ODEs were computed, and the simplification of the mechanism based on the concentration sensitivities was prospected. However, the details of the reduction processes were not presented. Furthermore, the reduction technique discussed in these studies (Cao and
Gutheil, 2013; Cao et al., 2014) is only limited to the concentration sensitivity analysis. Thus, in order to obtain an appropriate reaction mechanism of ODEs with reduced size and adequate accuracy so that the multi-dimensional simulations of ODEs are applicable, in the present study, two different approaches, concentration sensitivity analysis and principal component analysis, were applied in a multiphase box model. By doing that, we were able to identify the dominant reactions that govern the bromine chemistry and the ozone depletion during the Arctic spring from the original complex reaction mechanism, which in turn saves the computing time in the modeling work of ODEs. The results obtained by using these two mechanism simplification approaches are compared and discussed. The connection between different chemical reactions is also revealed during the reduction processes.

The manuscript is organized as follows. In Sect. 2, the governing equations of the reduction approaches used in this study are presented. The criteria for screening unimportant reactions from the original reaction scheme are also given in this section. Then the computational results of this work are shown in Sect. 3. Reduced reaction mechanisms derived after the analyses are presented and compared as well. The species in quasi-steady state is also revealed by the implementation of the principal component analysis. Finally, major conclusions made in the present study are addressed in Sect. 4. Further simplification of the reduced reaction mechanism is also prospected.

\section{Mathematical model and methods}

A complex chemical reaction system can be denoted as

$\frac{\mathrm{d} \boldsymbol{c}}{\mathrm{d} t}=\boldsymbol{f}(\boldsymbol{c}, \boldsymbol{k})+\boldsymbol{E}$,

with the initial condition $\left.\boldsymbol{c}\right|_{t=0}=\boldsymbol{c}_{0}$, where $\boldsymbol{c}$ is a column vector of species concentrations. $\boldsymbol{k}$ in Eq. (1) is a vector of reaction rate coefficients and $t$ denotes time. $\boldsymbol{E}$ represents the source term of local surface emissions. In the present study, a reaction mechanism with the involvement of bromine-containing compounds and nitrogen-related species is adopted from the previous box model study (Cao et al., 2014). Furthermore, the reaction rate constants are updated with the latest chemical kinetic data (Atkinson et al., 2006). Several photolysis reactions are also added to complete the previous reaction mechanism. The reaction scheme used in the present study consists of 39 chemical species and 92 reactions and is listed in the Supplement. In this chemical reaction mechanism, bromine is considered as the only halogen species, whereas the chlorine-related species and reactions are excluded. The influences brought about by the inclusion of the chlorine chemistry have discussed by Cao et al. (2014). As the focus of the present study is placed on the reduction of the reaction mechanism instead of pursuing a more precise 
prediction of the temporal change of each chemical species, the choice of this chlorine-free reaction mechanism does not affect the metrics of the present study.

As mentioned above, two different approaches, concentration sensitivity analysis and principal component analysis, are followed to reduce the size of the reaction mechanism of ODEs. The governing equations of these two approaches and the procedures of the mechanism simplification are presented below.

\subsection{Concentration sensitivity analysis}

The importance of the $j$ th reaction for the $i$ th chemical species is depicted by the relative concentration sensitivity $\widetilde{S}_{i j}$, which can be written in the form of

$\widetilde{S}_{i j}=\frac{\partial \ln c_{i}}{\partial \ln k_{j}}=\frac{k_{j}}{c_{i}} \frac{\partial c_{i}}{\partial k_{j}}=\frac{k_{j}}{c_{i}} S_{i j}$.

In Eq. (2), $c_{i}$ is the concentration of the $i$ th chemical species, and $k_{j}$ denotes the rate coefficient of the $j$ th reaction. $S_{i j}=$ $\partial c_{i} / \partial k_{j}$ is the absolute concentration sensitivity, and the unit of $S_{i j}$ depends on the order of the $j$ th reaction. In order to compare the sensitivity coefficients belonging to different reactions, the normalized version of the sensitivity coefficient, $\widetilde{S}_{i j}$, is introduced by multiplying $S_{i j}$ with $k_{j} / c_{i}$. The obtained relative concentration sensitivity $\widetilde{S}_{i j}$ is thus a dimensionless variable, which represents the percentage of change in the $i$ th species concentration due to a $1 \%$ change of the $j$ th reaction rate constant. The evaluation of the relative concentration sensitivity is helpful for discovering the interdependence between the solution of Eq. (1) and the input parameters such as the reaction rate constants $k_{j}$.

The calculation of $\widetilde{S}_{i j}$ is performed by differentiating the $i$-th component of Eq. (1) with respect to $k_{j}$. With the assumption that the local emissions are independent of the rate constants, Eq. (1) becomes

$\frac{\mathrm{d}\left(\partial c_{i} / \partial k_{j}\right)}{\mathrm{d} t}=\sum_{l=1}^{n_{s}} \frac{\partial f_{i}}{\partial c_{l}} \frac{\partial c_{l}}{\partial k_{j}}+\frac{\partial f_{i}}{\partial k_{j}}$.

The upper limit of the sum in Eq. (3), $n_{s}$, denotes the total number of the chemical species included in the model. By substituting $\partial c_{i} / \partial k_{j}$ and $\partial c_{l} / \partial k_{j}$ in Eq. (3) with the absolute concentration sensitivities $S_{i j}$ and $S_{l j}$, we obtain another form of Eq. (3) as follows,

$$
\frac{\mathrm{d} S_{i j}}{\mathrm{~d} t}=\sum_{l=1}^{n_{s}} \frac{\partial f_{i}}{\partial c_{l}} S_{l j}+\frac{\partial f_{i}}{\partial k_{j}} .
$$

The second term of the right-hand side of Eq. (4) denotes the direct influence on the concentration change of $i$ th species caused by the perturbation of the $j$ th reaction rate constant. Moreover, as a result of this direct variation in the $j$ th reaction rate, indirect effects on the concentrations of other species are induced via the coupled kinetic system, which contributes to the solution of Eq. (4). This indirect effect of parameter change is indicated by the first term of the right-hand side of Eq. (4). After obtaining the solution $S_{i j}$ of Eq. (4), the relative concentration sensitivity can be calculated by multiplying $S_{i j}$ with $k_{j} / c_{i}$. The computation of the absolute concentration sensitivity is conducted by using the subroutine SENS in the chemical kinetic software KINAL (Turányi, 1990a). The decomposed direct method (Valko and Vajda, 1984) is implemented in KINAL for solving Eq. (4), which has been proven to be robust and efficient (Turányi, 1990b).

The concentration sensitivity analysis is a useful measure of how sensitive a specified species concentration is to a particular reaction rate constant. Thus, reactions with large absolute values of sensitivities are identified as important and rate-determining. For the purpose of deriving an appropriate reduced reaction mechanism of ODEs, it is necessary to remove the least important reactions from the original reaction scheme. In the present study, we consider the $j$ th reaction as unimportant if the criterion

$\max \left|\widetilde{S}_{i j}(t)\right| \leq 10 \% ; i=1, \ldots, n_{s}, t=t(1), \ldots, t\left(n_{t}\right)$

is fulfilled. In Eq. (5), $n_{s}$ is the total number of the chemical species as mentioned above, and $n_{t}$ denotes the total time step in the computation. The criterion in Eq. (5) shows that the $j$ th reaction is considered as unimportant if its relative concentration sensitivity for all species at any time point is smaller than $10 \%$ and then can be eliminated from the system.

Although the concentration sensitivity analysis is powerful for constructing a minimal chemical reaction set describing ODEs, it has some disadvantages. As the concentration sensitivity represents the response of a system to a perturbation of the reaction rate at an earlier time point, the computed sensitivity coefficient is inherently time dependent, and its estimation depends on the adopted time interval. Thus, the concentration sensitivity obtained by solving Eq. (4) corresponds to a time interval instead of a fixed time point. A drawback brought about by this inherent time-dependent property of the concentration sensitivity is the "memory effect" (Vajda and Turányi, 1986; Turányi et al., 1989). Within the time interval for the integration of sensitivity coefficients, if a reaction is indicated as important at any stage of the time interval, it is identified as important during the whole time interval since this property is maintained in the concentration sensitivity analysis. As a result, this reaction cannot be eliminated from the original reaction scheme. In addition, although the concentration sensitivity analysis is capable of clarifying the dependence of species concentrations upon a particular rate coefficient, usually the species concentrations are influenced by a combination of input parameters such as a ratio of two reaction rate constants. This interdependence between the species concentrations and the groups of parameters can hardly be revealed by the concentration sensitivity analysis. Therefore, in the present study, another mechanism 
reduction approach is chosen, namely, the principal component analysis, and applied to the original reaction mechanism of ODEs, which is discussed in the section below.

\subsection{Principal component analysis}

The principal component analysis provides an effective means of screening unimportant reactions from a complex reaction scheme so that a tractable reaction mechanism can be derived. To perform the principal component analysis, we first introduce the normalized rate parameter, $\boldsymbol{\alpha}$, of which the $j$ th component can be expressed as

$\alpha_{j}=\ln k_{j}, j=1, \ldots, n_{p}$.

Herein, $n_{p}$ denotes the total number of the chemical reactions considered in the model.

The definition given by Eq. (6) enables one to express the response of the reaction mechanism due to a variation in the rate parameters, $\boldsymbol{\alpha}$, using the response function $Q(\boldsymbol{\alpha})$ as follows:

$$
Q(\boldsymbol{\alpha})=\sum_{m=1}^{n_{t}} \sum_{i=1}^{n_{s}}\left[\frac{c_{i, m}(\boldsymbol{\alpha})-c_{i, m}\left(\boldsymbol{\alpha}^{0}\right)}{c_{i, m}\left(\boldsymbol{\alpha}^{0}\right)}\right]^{2} .
$$

In Eq. (7), the subscript " $i, m$ " represents the concentration of $i$ th species at the $m$ th time point. $n_{s}$ and $n_{t}$ are the total number of the chemical species and the time step, respectively. $\boldsymbol{\alpha}^{0}$ denotes a matrix of the normalized rate parameters with original values.

By applying a Taylor series expansion (Vajda et al., 1985) and a Gauss approximation (Bard, 1974) on Eq. (7), the response function $Q(\boldsymbol{\alpha})$ is approximated as

$Q(\boldsymbol{\alpha}) \approx \widetilde{Q}(\boldsymbol{\alpha})=(\Delta \boldsymbol{\alpha})^{\mathrm{T}} \widetilde{\boldsymbol{S}}^{\mathrm{T}} \widetilde{\boldsymbol{S}}(\Delta \boldsymbol{\alpha})$.

Herein, $\widetilde{Q}(\boldsymbol{\alpha})$ is an approximate response function. $\Delta \boldsymbol{\alpha}$ denotes a column vector of the parameter perturbations, which has the $j$ th component,

$\Delta \alpha_{j}=\ln \alpha_{j}-\ln \alpha_{j}^{0}$.

$\widetilde{\boldsymbol{S}}$ in Eq. (8) represents an array of the relative concentration sensitivities corresponding to the time instance $t(m), m=$ $1, \ldots, n_{t}$, and the $m$ th element of $\widetilde{\boldsymbol{S}}$ has the form of

$\widetilde{S}_{m}=\left(\begin{array}{cccc}\frac{\partial \ln c_{1, m}}{\partial \ln k_{1}} & \frac{\partial \ln c_{1, m}}{\partial \ln k_{2}} & \ldots & \frac{\partial \ln c_{1, m}}{\partial \ln k_{n}} \\ \frac{\partial \ln c_{2, m}}{\partial \ln k_{1}} & \frac{\partial \ln c_{2, m}}{\partial \ln k_{2}} & \ldots & \frac{\partial \ln c_{2, m}}{\partial \ln k_{n_{p}}} \\ \vdots & \vdots & \ddots & \vdots \\ \frac{\partial \ln c_{n_{s}, m}}{\partial \ln k_{1}} & \frac{\partial \ln c_{n_{s}, m}}{\partial \ln k_{2}} & \ldots & \frac{\partial \ln c_{n_{s}, m}}{\partial \ln k_{n_{p}}}\end{array}\right)$.

$\widetilde{\boldsymbol{S}}$ is, thus, a matrix with a dimension of $\left(n_{t} \cdot n_{s}\right) \times n_{p}$. The eigenvalue-eigenvector decomposition technique is then applied on the matrix $\widetilde{\boldsymbol{S}}^{\mathrm{T}} \widetilde{\boldsymbol{S}}$ in Eq. (8), which leads to

$\widetilde{\boldsymbol{S}}^{\mathrm{T}} \widetilde{\boldsymbol{S}}=\boldsymbol{U} \boldsymbol{\Lambda} \boldsymbol{U}^{\mathrm{T}}$, where $\boldsymbol{U}$ is a matrix of normed eigenvectors of $\widetilde{\boldsymbol{S}}^{\mathrm{T}} \widetilde{\boldsymbol{S}} . \boldsymbol{\Lambda}$ represents a diagonal matrix consisting of the eigenvalues $\lambda_{1}, \lambda_{2}, \ldots, \lambda_{n_{p}}$ of $\widetilde{\boldsymbol{S}}^{\mathrm{T}} \widetilde{\boldsymbol{S}}$. By replacing $\widetilde{\boldsymbol{S}}^{\mathrm{T}} \widetilde{\boldsymbol{S}}$ in Eq. (8) with the expression shown in Eq. (11), we obtain the approximate response function in the form of

$\widetilde{Q}(\boldsymbol{\alpha})=(\Delta \boldsymbol{\alpha})^{\mathrm{T}} \boldsymbol{U} \boldsymbol{\Lambda} \boldsymbol{U}^{\mathrm{T}}(\Delta \boldsymbol{\alpha})$.

We then define the principal component $\boldsymbol{\Psi}=\boldsymbol{U}^{\mathrm{T}} \boldsymbol{\alpha}$ in order to write $\boldsymbol{U}^{\mathrm{T}}(\Delta \boldsymbol{\alpha})$ in the above equation as a variation of the principal component,

$\Delta \boldsymbol{\Psi}=\boldsymbol{U}^{\mathrm{T}}(\Delta \boldsymbol{\alpha})$.

As a result of the definition of the principal component, Eq. (12) becomes

$\widetilde{Q}(\boldsymbol{\alpha})=\widetilde{Q}(\boldsymbol{\Psi})=\sum_{j=1}^{n_{p}} \lambda_{j}\left\|\Delta \Psi_{j}\right\|^{2}$,

wherein $\left\|\Delta \Psi_{j}\right\|^{2}=\left(\Delta \Psi_{j}\right)^{\mathrm{T}}\left(\Delta \Psi_{j}\right)$. From Eq. (14), it can be seen that the eigenvalue $\lambda_{j}$ depicts the significance of a group of reactions for the change of the system. $\Delta \Psi_{j}$ in Eq. (14) consists of $n_{p}$ elements, which correspond to closely interacting reactions in the original complex reaction system. It denotes that the species concentrations are influenced not only by a separate individual reaction but also a closely intertwining reaction sequence. Moreover, the contribution of the individual reaction to its group is also indicated by the weight of the corresponding element in the eigenvectors. Thus, by performing the principal component analysis on the matrix $\widetilde{\boldsymbol{S}}^{\mathrm{T}} \widetilde{\boldsymbol{S}}$, important reactions can be indicated if they correspond to a large element of a principal component associated with a large eigenvalue.

Therefore, after obtaining the relative sensitivity coefficient $\widetilde{S}_{i j}$ of the reaction mechanism representing the chemistry of ODEs, principal component analysis is performed on the matrix $\widetilde{\boldsymbol{S}}^{\mathrm{T}} \widetilde{\boldsymbol{S}}$. In that way $n_{p}$ eigenvalues and the associated eigenvectors are obtained. In order to derive a reaction mechanism with reduced size, we remove the reactions belonging to the principal components with small eigenvalues. It has been proven in previous studies (Vajda et al., 1985) that if the eigenvalue $\lambda_{j}$ is smaller than $n_{s} \times n_{t} \times 10^{-4}$, the variation in the concentration of each chemical species in the system is less than $10 \%$ at each instance in time. This selection criterion is also adopted in the present study. Aside from this, in the principal components corresponding to large eigenvalues, elements with values less than 0.2 are also considered as unimportant and, thus, can be removed from the original mechanism. It was estimated that these elements contribute less than $4 \%$ to the total variation of the concentrations (Vajda et al., 1985).

It should also be noted that by removing the $j$ th reaction from the original chemical system, we actually define the 
Table 1. Initial atmospheric composition in the $200 \mathrm{~m}$ boundary layer (ppm is parts per million, ppb is parts per billion, ppt is parts per trillion) (Cao et al., 2014).

\begin{tabular}{lr}
\hline Species & Mixing ratio \\
\hline $\mathrm{O}_{3}$ & $40 \mathrm{ppb}$ \\
$\mathrm{Br}_{2}$ & $0.3 \mathrm{ppt}$ \\
$\mathrm{HBr}$ & $0.01 \mathrm{ppt}$ \\
$\mathrm{CH}_{4}$ & $1.9 \mathrm{ppm}$ \\
$\mathrm{CO}_{2}$ & $371 \mathrm{ppm}$ \\
$\mathrm{CO}$ & $132 \mathrm{ppb}$ \\
$\mathrm{HCHO}$ & $100 \mathrm{ppt}$ \\
$\mathrm{CH}_{3} \mathrm{CHO}$ & $100 \mathrm{ppt}$ \\
$\mathrm{C}_{2} \mathrm{H}_{6}$ & $2.5 \mathrm{ppb}$ \\
$\mathrm{C}_{2} \mathrm{H}_{4}$ & $100 \mathrm{ppt}$ \\
$\mathrm{C}_{2} \mathrm{H}_{2}$ & $600 \mathrm{ppt}$ \\
$\mathrm{C}_{3} \mathrm{H}_{8}$ & $1.2 \mathrm{ppb}$ \\
$\mathrm{NO}$ & $5 \mathrm{ppt}$ \\
$\mathrm{NO}_{2}$ & $10 \mathrm{ppt}$ \\
$\mathrm{H}_{2} \mathrm{O}$ & $800 \mathrm{ppm}$ \\
\hline
\end{tabular}

reaction rate constant of the $j$ th reaction $k_{j}=0$, for which Eq. (6) is invalid. To solve this problem, the parameter

$\widetilde{\alpha}_{j}=\frac{k_{j}}{k_{j}^{0}}, j=1, \ldots, n_{p}$

is introduced (Vajda et al., 1985). It can be easily deduced that $\widetilde{\alpha}_{j}$ and the parameter $\alpha_{j}$ discussed above yield the same normalized sensitivity $\widetilde{S}_{i j}$. Therefore, the investigation of $\widetilde{\boldsymbol{S}}^{\mathrm{T}} \widetilde{\boldsymbol{S}}$ for $\alpha_{j}$ described in the present manuscript is also valid for $\widetilde{\alpha}_{j}$ in the simplification process of the reaction mechanism.

Thus, at first, the original reaction mechanism described above is implemented in the box model KINAL (Turányi, 1990a) to capture the temporal behavior of ozone and principal bromine species. The boundary layer height used in the model is defined as $200 \mathrm{~m}$. This is considered to be a representative value since the boundary layer height under typical polar conditions ranges from 100 to $500 \mathrm{~m}$ (Stull, 1988). The initial atmospheric composition used in the model is listed in Table 1, taken from the previous box model study (Cao et al., 2014). In the present model, the prescribed 0.3 ppt $\mathrm{Br}_{2}$ and $0.01 \mathrm{ppt} \mathrm{HBr}$ play the role of triggering the bromine explosion mechanism and the associated ozone consumption. Emissions of nitrogen oxides $\left(\mathrm{NO}_{x}\right), \mathrm{HONO}, \mathrm{H}_{2} \mathrm{O}_{2}$, and $\mathrm{HCHO}$ from the underlying surface are also implemented in the model according to the measurements (Jones et al., 2000, 2001; Jacobi et al., 2002; Grannas et al., 2007), and listed in Table 2. The ratio of $\mathrm{HONO}$ and $\mathrm{NO}_{2}$ is assumed to be in unity (Grannas et al., 2007).

The photolysis frequencies $J$ are evaluated by using a three-coefficient function,

$J=J_{0} \exp (b[1-\sec (c \chi)])$
Table 2. Emission fluxes from the underlying surface (Cao et al., 2014).

\begin{tabular}{lrl}
\hline Species & $\begin{array}{r}\text { Emission rates } \\
{\left[\text { molec. cm }{ }^{-2} \mathrm{~s}^{-1}\right]}\end{array}$ & Reference \\
\hline $\mathrm{NO}$ & $1.6 \times 10^{7}$ & Jones et al. (2000, 2001) \\
$\mathrm{NO}_{2}$ & $1.6 \times 10^{7}$ & Jones et al. (2000, 2001) \\
$\mathrm{HONO}$ & $1.6 \times 10^{7}$ & Grannas et al. (2007) \\
$\mathrm{H}_{2} \mathrm{O}_{2}$ & $1.0 \times 10^{8}$ & Jacobi et al. (2002) \\
$\mathrm{HCHO}$ & $6.0 \times 10^{7}$ & Jacobi et al. (2002) \\
\hline
\end{tabular}

in a three-stream radiation transfer model (Röth, 1992, 2002) with an assumption of SZA (solar zenith angle) $=80^{\circ}$ and a surface albedo unity. In Eq. (16), $\chi$ denotes the value of SZA. The coefficients $J_{0}, b$, and $c$ are determined in the model by Röth (2002) under the conditions of $\mathrm{SZA}=0,60$, and $90^{\circ}$. The values of these parameters, $J_{0}, b$, and $c$, used in the present model can be found in our earlier publications (Cao et al., 2014, 2016a). At present, the daily variation in SZA and the dark reactions are not accounted for in the model. The influences brought about by the inclusion of the change in SZA and the dark reactions have been proven to be small in previous investigations (Lehrer et al., 2004; Cao et al., 2014, 2016a).

The heterogeneous reactions representing the bromine recycling processes on the surfaces of the ice-/snowpack and the suspended aerosols are also included in the original reaction mechanism of ODEs. It has been proven that the rates of these heterogeneous reactions critically control the bromine amount in the boundary layer and the depletion rate of ozone during ODEs (Cao et al., 2014). In the present study, the parameterizations of these heterogeneous reactions are also adopted from the box model study by Cao et al. (2014). For the reactions occurring on or in the suspended aerosols (see Reactions SR14 and SR90 in the Supplement), we adopted a function in the form of Eq. (17) to estimate the reaction rate constant $k_{\text {aerosol }}$ :

$k_{\text {aerosol }}=\left(\frac{r}{D_{\mathrm{g}}}+\frac{4}{v_{\text {therm }} \gamma}\right)^{-1} \alpha_{\text {eff, aerosol }}$.

In Eq. (17), $r=0.3 \mu \mathrm{m}$ is the average radius of the suspended aerosols under typical Arctic conditions. $D_{\mathrm{g}}=0.2 \mathrm{~cm}^{2} \mathrm{~s}^{-1}$ represents the molecular diffusivity. $v_{\text {therm }}=\sqrt{8 R T /(\pi M)}$ denotes the thermal speed of gas-phase $\mathrm{HOBr}$ and $\mathrm{BrONO}_{2}$ for Reactions (SR14) and (SR90), respectively. $\gamma$ in Eq. (17) represents the uptake coefficient of $\mathrm{HOBr}$ or $\mathrm{BrONO}_{2}$ by the suspended aerosols. The value of $\gamma$ for $\mathrm{HOBr}$ is estimated by using the method of Hanson et al. (1994), depending on the rate of the aqueous reaction between $\mathrm{HOBr}$ and $\mathrm{HBr}$. In contrast, we assumed a constant value $(\gamma=0.06)$ for $\mathrm{BrONO}_{2}$, according to the model study of Sander and Crutzen (1996).

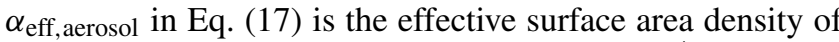
the suspended aerosols, and is computed as $10^{-4} \mathrm{~m}^{-1}$ when 
the aerosol volume fraction is set equal to $10^{-5} \mathrm{~cm}^{3} \mathrm{~m}^{-3}$ in the present model (Lehrer et al., 2004). With respect to the heterogeneous reactions on the ground surface covered by ice and snow, i.e., Reactions (SR15) and (SR92) in the Supplement, the calculation of their rates requires the consideration of the aerodynamic resistance $r_{a}$, quasi-laminar resistance $r_{b}$, and surface resistance $r_{c}$ in the model. A typical wind speed observed in the Arctic spring $\left(8 \mathrm{~m} \mathrm{~s}^{-1}\right.$; Beare et al., 2006) and a roughness length for the ice surface $\left(10^{-5} \mathrm{~m}\right.$; Stull, 1988) are adopted in the estimations of these resistances. Moreover, the surface area density of the ground surface, $\alpha_{\text {eff, ice }}=5 \times 10^{-3} \mathrm{~m}^{-1}$ is obtained with an assumption of a $200 \mathrm{~m}$ boundary layer. As a result, the mass transfer coefficient $k_{\text {ice }}$ for the heterogeneous Reactions (SR15) and (SR92) is calculated as

$k_{\text {ice }}=\left(r_{a}+r_{b}+r_{c}\right)^{-1} \alpha_{\text {eff,ice }}$.

The details of the parameterization of the mass transfer coefficient are given by Lehrer et al. (2004) and Cao et al. (2014). Recently, a snowpack module representing the mass exchange between the porous snowpack and the ambient air was developed by the author and co-workers (Cao et al., 2016c). However, this snowpack module was not applied in the reaction mechanism used in the present study.

Later, the concentration sensitivity analysis is applied on the original reaction mechanism of ODEs to identify the most influential reactions during different time periods. The temporal behavior of the concentration sensitivity coefficient for each reaction is also captured. Then the reactions with a maximum absolute value of the relative concentration sensitivity less than $10 \%$ are removed from the original reaction scheme so that a reduced reaction mechanism is obtained.

After the computation of the relative concentration sensitivity coefficients, the principal component analysis is performed on the matrix $\widetilde{\boldsymbol{S}}^{\mathrm{T}} \widetilde{\boldsymbol{S}}$. Principal components corresponding to small eigenvalues are regarded as making negligible contributions to the overall response of the whole system and, thus, can be eliminated. Since 38 chemical species (all species in the mechanism excluding $\mathrm{N}_{2}$ ) and 94 time steps are focused on in the present simulation, the criterion of eigenvalues used for dividing important and unimportant principal components is calculated as $38 \times 94 \times 10^{-4}=$ 0.3572 . Moreover, as discussed above, if an element in a relatively important principal component has a value of less than 0.2 , this element can be also removed due to its relatively small contribution to the total variation of the system.

In the following section, the most important computational results are presented and discussed.

\section{Results and discussion}

At the beginning of this study, we ran the box model KINAL with the implementation of the original complex reaction scheme to capture the temporal change of principal

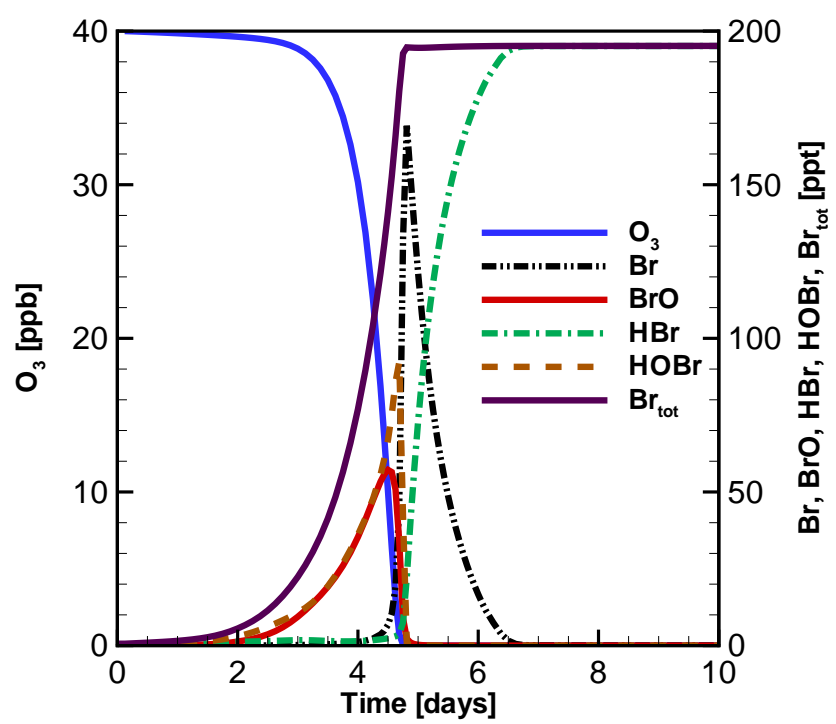

Figure 1. Temporal evolution of ozone and principal brominecontaining compounds in a $200 \mathrm{~m}$ boundary layer, obtained by using the original reaction scheme in the model (Cao et al., 2016a).

chemical species within the $200 \mathrm{~m}$ boundary layer. Figure 1 displays the development of the mixing ratios of ozone and principal bromine species with time. According to previous studies (Cao et al., 2014), the whole ODE can be divided into three periods. In the first period, named "induction stage", which corresponds to the time period before day 3 in Fig. 1, the consumption rate of ozone in the boundary layer is less than $0.1 \mathrm{ppbh}^{-1}$. Moreover, the mixing ratio of ozone remains steady at a background level ( $\sim 40 \mathrm{ppb})$. Due to the presence of ozone in this time period, the formed $\mathrm{Br}$ atoms are rapidly oxidized to be $\mathrm{BrO}$, and thus can be hardly observed at this time stage. In contrast to that, the mixing ratios of $\mathrm{HOBr}$ and $\mathrm{BrO}$ steadily increase within this time period, which makes them the major bromine-containing compounds.

After day 3 (see Fig. 1), as bromide is continuously activated from the ice/snow surface via the bromine explosion mechanism, the total bromine loading in the ambient air keeps increasing. As a result, the depletion rate of ozone exceeds $0.1 \mathrm{ppb} \mathrm{h}^{-1}$, and the mixing ratio of ozone declines rapidly until a value lower than $10 \%$ of its original level $(4 \mathrm{ppb})$ is achieved, on approximately day 4.6. This period (from day 3 to day 4.6) is thus named the "depletion stage". Within the depletion stage, the mixing ratios of $\mathrm{BrO}$ and $\mathrm{HOBr}$ reach their peaks and then drop instantaneously to a level less than $1 \mathrm{ppt}$ due to the nearly complete removal of ozone in the boundary layer.

After the depletion stage, the last time period of the ODE is the "end stage" in which the ozone mixing ratio is lower than $4 \mathrm{ppb}$. At the beginning of the end stage, $\mathrm{Br}$ atom becomes the most dominant brominated species and its mixing ratio increases to a peak value of approximately $170 \mathrm{ppt}$ (see the 
(a)
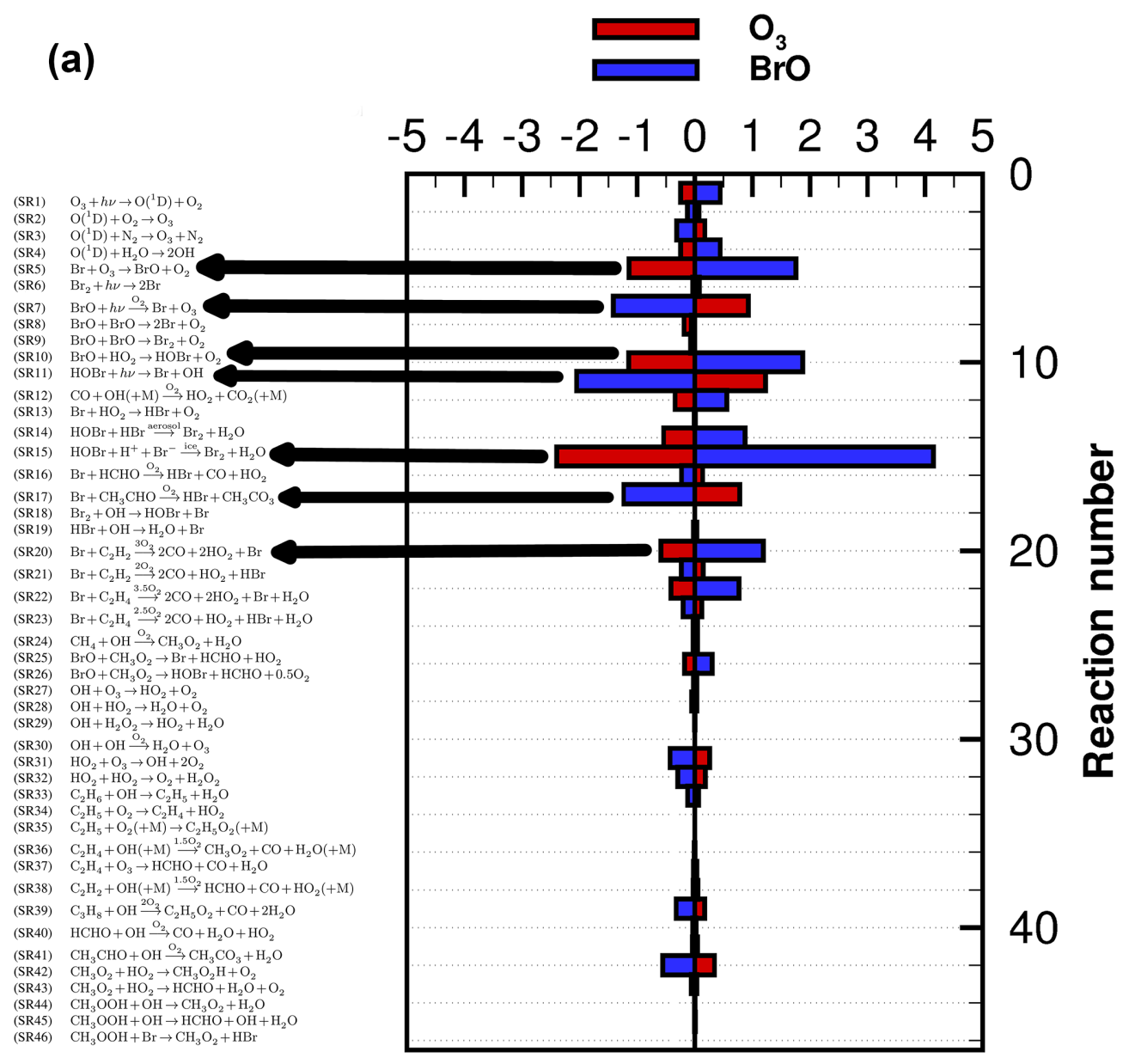

Figure 2.

black line in Fig. 1). This large amount of $\mathrm{Br}$ is then absorbed by the aldehydes in the atmosphere, and the total bromine amount left in the ambient air becomes steady towards the end of the simulation (see the purple solid line in Fig. 1). After day 6 , the dominant bromine species in the ambient air is mostly in the form of $\mathrm{HBr}$, which is consistent with the previous finding (Langendörfer et al., 1999). The features of the temporal change of these chemical species are similar to those obtained in previous studies (Lehrer et al., 2004; Cao et al., 2014, 2016b, c) except a slight difference in the onsets of the aforementioned time periods. The discrepancy between the results from different model studies is attributed to the extension of the previous reaction mechanism in the present study.

After capturing the temporal behavior of principal chemical species, the original reaction mechanism consisting of 39 species and 92 reactions is processed with the concentration sensitivity analysis, which is shown in the next subsection.

\subsection{Concentration sensitivity analysis of the reaction mechanism of the ODE}

The relative concentration sensitivity coefficient of each chemical species for all the reactions in the original mechanism within each time step is calculated by performing the concentration sensitivity analysis. Figure 2 depicts the sensitivity coefficients of ozone and $\mathrm{BrO}$ for all the reactions in the mechanism within the time interval [day 3.9, day 4] which resides within the depletion stage. It can be seen that the sensitivities of the mixing ratios of ozone and $\mathrm{BrO}$ to each chemical reaction in the mechanism are clearly indicated by the values of the sensitivity coefficients.

In Fig. 2a, Reaction (SR15), which denotes the heterogeneous bromine activation from the ice-/snow-covered surfaces, is identified as the most important reaction for both ozone and $\mathrm{BrO}$ mixing ratios at this time stage. This is related to the fact that during the depletion stage, the $\mathrm{HOBr}$ concentration increases vigorously until its peak value is achieved. Thus, a large amount of bromide is activated from the ice/snow surfaces. As a result, Reaction (SR15) critically determines the total bromine amount in the air and the deple- 
(b)
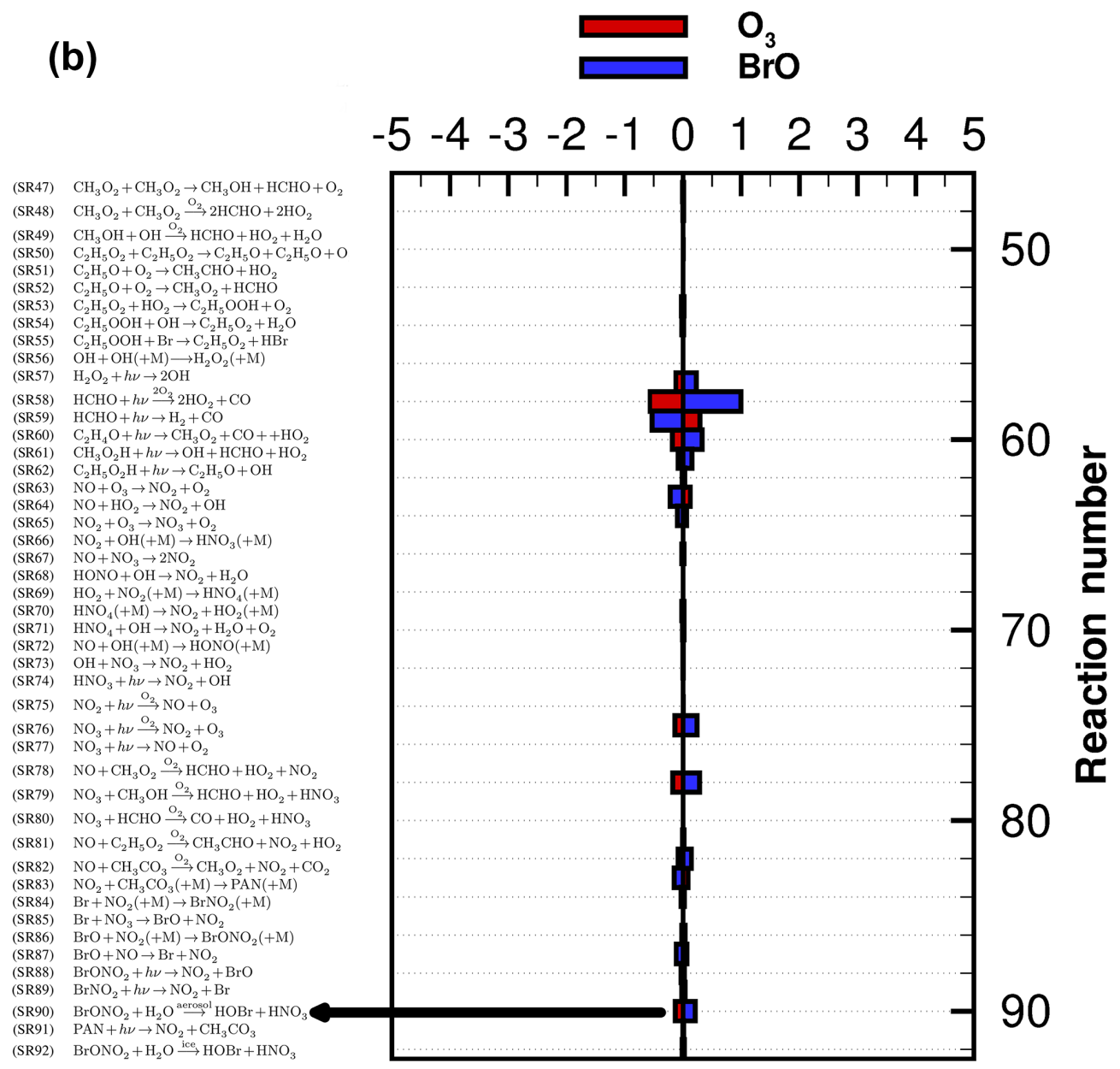

Figure 2. Relative concentration sensitivities of ozone and BrO for (a) Reactions (SR1)-(SR46) and (b) Reactions (SR47)-(SR92) within the time interval [day 3.9, day 4].

tion rate of ozone in this time period. Due to the same reason, reactions with the involvement of $\mathrm{HOBr}$, Reactions (SR10) and (SR11), play significant roles in influencing the mixing ratios of ozone and $\mathrm{BrO}$, which is indicated in Fig. 2a. Aside from the reactions associated with $\mathrm{HOBr}$, reactions which are able to produce or consume $\mathrm{Br}$ atoms are also influential since $\mathrm{Br}$ reacts with ozone directly and rapidly. Thus, the significance of the Br-associated reactions, Reactions (SR5), (SR7), (SR17), and (SR20), is displayed in Fig. 2a according to the relatively large absolute values of the sensitivity coefficients. By evaluating the sensitivities at an earlier time instance (not shown here), we found that the $\mathrm{Br}$-associated reactions are the most dominant reactions for ozone and $\mathrm{BrO}$ in the induction stage. However, from Fig. 2a, it can be concluded that during the depletion stage, the importance of the $\mathrm{HOBr}$-associated reactions exceed the ones with the involvement of $\mathrm{Br}$ atoms.

In Fig. $2 b$, it is shown that the nitrogen-related reactions are less important for the mixing ratios of ozone and $\mathrm{BrO}$ in the boundary layer compared to the bromine-related reac- tions. However, the moderate role of the hydrolysis reaction of $\mathrm{BrONO}_{2}$, Reaction (SR90), is depicted. The reason is attributable to the formation of $\mathrm{HOBr}$ in this reaction, which may also speed up the bromine activation during this time period. Moreover, we found that the reactions with the involvement of $\mathrm{BrONO}_{2}$ are of more importance during the end stage, which is consistent with the previous box model study (Cao et al., 2014).

The results discussed above show that the values of the concentration sensitivity coefficients vary with time. This reveals that the importance of each reaction differs significantly during different time periods. In order to clarify the temporal behavior of the concentration sensitivities, we also captured the development of the sensitivities of ozone for the dominant reactions with time (see Fig. 3). Similar to the results shown in Fig. 2, it is seen in Fig. 3 that the HOBrassociated reactions, Reactions (SR10), (SR11), and (SR15), are the most influential reactions for the ozone mixing ratio during the depletion stage and the beginning of the end stage as well. The maximum absolute values of the sensitivi- 
Table 3. The maximum absolute value of the concentration sensitivity coefficient for each reaction in the mechanism and the time when the maximum value occurs. Reaction number underlined denotes that this reaction is identified as unimportant via the concentration sensitivity analysis, and reaction number in bold represents that this reaction is indicated as unimportant via the principal component analysis.

\begin{tabular}{|c|c|c|c|c|c|c|c|c|}
\hline $\begin{array}{l}\text { Reaction } \\
\text { number }\end{array}$ & $\begin{array}{c}\text { Sensitivity } \\
\text { maximum }\end{array}$ & $\begin{array}{r}\text { Occurring } \\
\text { day }\end{array}$ & $\begin{array}{l}\text { Reaction } \\
\text { number }\end{array}$ & $\begin{array}{l}\text { Sensitivity } \\
\text { maximum }\end{array}$ & $\begin{array}{r}\text { Occurring } \\
\text { day }\end{array}$ & $\begin{array}{l}\text { Reaction } \\
\text { number }\end{array}$ & $\begin{array}{c}\text { Sensitivity } \\
\text { maximum }\end{array}$ & $\begin{array}{r}\text { Occurring } \\
\text { day }\end{array}$ \\
\hline (SR1) & $3.1 \times 10^{1}$ & 4.75 & (SR32) & $2.0 \times 10^{1}$ & 4.75 & (SR63) & $1.5 \times 10^{1}$ & 4.75 \\
\hline (SR2) & $8.9 \times 10^{0}$ & 4.75 & (SR33) & $9.6 \times 10^{0}$ & 4.75 & (SR64) & $6.9 \times 10^{0}$ & 4.75 \\
\hline (SR3) & $2.2 \times 10^{1}$ & 4.75 & (SR34) & $1.0 \times 10^{0}$ & 5.0 & (SR65) & $7.9 \times 10^{-1}$ & 0.1 \\
\hline (SR4) & $3.1 \times 10^{1}$ & 4.75 & (SR35) & $1.0 \times 10^{0}$ & 4.6 & (SR66) & $1.5 \times 10^{0}$ & 4.75 \\
\hline (SR5) & $1.1 \times 10^{2}$ & 4.75 & (SR36) & $1.2 \times 10^{0}$ & 4.8 & (SR67) & $1.3 \times 10^{-2}$ & 0.1 \\
\hline (SR6) & $6.1 \times 10^{0}$ & 4.75 & (SR37) & $2.3 \times 10^{0}$ & 4.75 & (SR68) & $4.7 \times 10^{-1}$ & 4.3 \\
\hline (SR7) & $8.7 \times 10^{1}$ & 4.75 & (SR38) & $4.1 \times 10^{0}$ & 4.75 & (SR69) & $1.8 \times 10^{0}$ & 2.1 \\
\hline (SR8) & $2.0 \times 10^{1}$ & 4.75 & (SR39) & $2.5 \times 10^{1}$ & 4.75 & (SR70) & $2.9 \times 10^{0}$ & 2.1 \\
\hline (SR9) & $3.2 \times 10^{0}$ & 10.0 & (SR40) & $2.7 \times 10^{0}$ & 4.75 & (SR71) & $9.2 \times 10^{-2}$ & 4.75 \\
\hline (SR10) & $1.3 \times 10^{2}$ & 4.75 & (SR41) & $4.8 \times 10^{0}$ & 2.0 & $\overline{(\text { SR72) }}$ & $4.0 \times 10^{-1}$ & 4.75 \\
\hline (SR11) & $1.4 \times 10^{2}$ & 4.75 & (SR42) & $3.8 \times 10^{1}$ & 4.75 & (SR73) & $8.6 \times 10^{-5}$ & 4.75 \\
\hline (SR12) & $3.9 \times 10^{1}$ & 4.75 & (SR43) & $4.0 \times 10^{0}$ & 4.75 & (SR74) & $5.2 \times 10^{-2}$ & 4.75 \\
\hline (SR13) & $9.9 \times 10^{0}$ & 10.0 & (SR44) & $1.8 \times 10^{0}$ & 10.0 & (SR75) & $1.7 \times 10^{1}$ & 4.75 \\
\hline (SR14) & $6.0 \times 10^{1}$ & 4.75 & (SR45) & $1.0 \times 10^{0}$ & 10.0 & (SR76) & $9.0 \times 10^{-1}$ & 2.1 \\
\hline (SR15) & $2.9 \times 10^{2}$ & 4.75 & (SR46) & $3.8 \times 10^{0}$ & 10.0 & (SR77) & $1.1 \times 10^{-1}$ & 6.6 \\
\hline (SR16) & $1.7 \times 10^{1}$ & 4.75 & (SR47) & $9.8 \times 10^{-1}$ & 0.1 & (SR78) & $1.9 \times 10^{1}$ & 4.75 \\
\hline (SR17) & $8.2 \times 10^{1}$ & 4.75 & (SR48) & $7.9 \times 10^{-1}$ & 10.0 & (SR79) & $3.9 \times 10^{-8}$ & 10.0 \\
\hline (SR18) & $8.7 \times 10^{-2}$ & 10.0 & (SR49) & $3.5 \times 10^{-2}$ & 4.75 & $\overline{\text { (SR80) }}$ & $6.0 \times 10^{-5}$ & 4.75 \\
\hline$\overline{(\text { SR19) }}$ & $2.3 \times 10^{0}$ & 4.75 & (SR50) & $1.6 \times 10^{0}$ & 7.2 & (SR81) & $1.4 \times 10^{0}$ & 4.75 \\
\hline (SR20) & $1.0 \times 10^{2}$ & 4.75 & (SR51) & $1.0 \times 10^{0}$ & 4.8 & (SR82) & $1.0 \times 10^{1}$ & 4.75 \\
\hline (SR21) & $2.5 \times 10^{1}$ & 10.0 & (SR52) & $4.3 \times 10^{-2}$ & 7.0 & (SR83) & $1.0 \times 10^{1}$ & 4.75 \\
\hline (SR22) & $5.7 \times 10^{1}$ & 4.75 & $\overline{(\text { SR53) }}$ & $2.4 \times 10^{0}$ & 4.75 & (SR84) & $2.6 \times 10^{0}$ & 4.75 \\
\hline (SR23) & $1.2 \times 10^{1}$ & 4.8 & (SR54) & $2.0 \times 10^{0}$ & 4.75 & (SR85) & $3.3 \times 10^{-1}$ & 4.8 \\
\hline (SR24) & $2.2 \times 10^{0}$ & 2.0 & (SR55) & $1.3 \times 10^{1}$ & 8.7 & (SR86) & $2.7 \times 10^{0}$ & 2.0 \\
\hline (SR25) & $3.3 \times 10^{0}$ & 4.75 & (SR56) & $3.4 \times 10^{-4}$ & 4.75 & (SR87) & $8.0 \times 10^{0}$ & 4.75 \\
\hline (SR26) & $2.0 \times 10^{1}$ & 4.75 & $\overline{(\text { SR57) }}$ & $1.7 \times 10^{1}$ & 4.75 & (SR88) & $2.3 \times 10^{0}$ & 4.75 \\
\hline (SR27) & $2.5 \times 10^{0}$ & 4.75 & (SR58) & $7.1 \times 10^{1}$ & 4.75 & (SR89) & $3.6 \times 10^{0}$ & 7.0 \\
\hline (SR28) & $3.9 \times 10^{0}$ & 4.75 & (SR59) & $3.7 \times 10^{1}$ & 4.75 & (SR90) & $1.4 \times 10^{1}$ & 4.75 \\
\hline (SR29) & $2.1 \times 10^{-1}$ & 4.75 & (SR60) & $2.3 \times 10^{1}$ & 4.75 & (SR91) & $1.4 \times 10^{0}$ & 10.0 \\
\hline (SR30) & $1.4 \times 10^{-4}$ & 4.75 & (SR61) & $1.1 \times 10^{1}$ & 4.75 & (SR92) & $1.6 \times 10^{0}$ & 4.75 \\
\hline$\overline{\text { (SR31) }}$ & $2.9 \times 10^{1}$ & 4.75 & (SR62) & $2.0 \times 10^{0}$ & 4.75 & & & \\
\hline
\end{tabular}

ties corresponding to Reactions (SR10), (SR11), and (SR15) are 71, 78, and 164, respectively. The second most important reactions are the Br-associated reactions, Reactions (SR5), (SR7), (SR17), and (SR20) (see Fig. 3). However, the values of their sensitivity coefficients are much lower than those of the $\mathrm{HOBr}$-related reactions during the time period under investigation.

Aiming to reduce the size of the original reaction mechanism, we summarize the maximum absolute values of the concentration sensitivities for each reaction in the original mechanism (see Table 3). Then the reactions with the maximum absolute value lower than $10 \%$ are removed from the mechanism. As a result, 11 reactions, namely, Reactions (SR18), (SR30), (SR49), (SR52), (SR56), (SR67), (SR71), (SR73), (SR74), (SR79), and (SR80), are eliminated from the original reaction mechanism of ODEs. The reduced reaction mechanism obtained after the simplification process, thus, contains 39 species and 81 reactions in total.

We applied the reduced reaction mechanism in the box model KINAL to see the deviations from the original reaction scheme. Figure 4 shows a comparison of the mixing ratios of ozone and principal bromine species computed by using the original reaction mechanism and the reduced reaction mechanism. It is found that both simulations give nearly identical results. The depletion stage of the ODE predicted by the reduced reaction mechanism lasts from day 3 to day 4.6, which is consistent with the results obtained by using the original reaction scheme. The maximum deviations of the mixing ratios of $\mathrm{Br}, \mathrm{HBr}, \mathrm{HOBr}, \mathrm{BrO}$, and $\mathrm{Br}_{\text {tot }}$ between the original reaction mechanism and the reduced reaction mechanism are $0.6,0.5,0.6,0.1$, and $0.2 \%$, respectively. Thus, it can be seen that the calculated concentration changes of ozone and prin- 


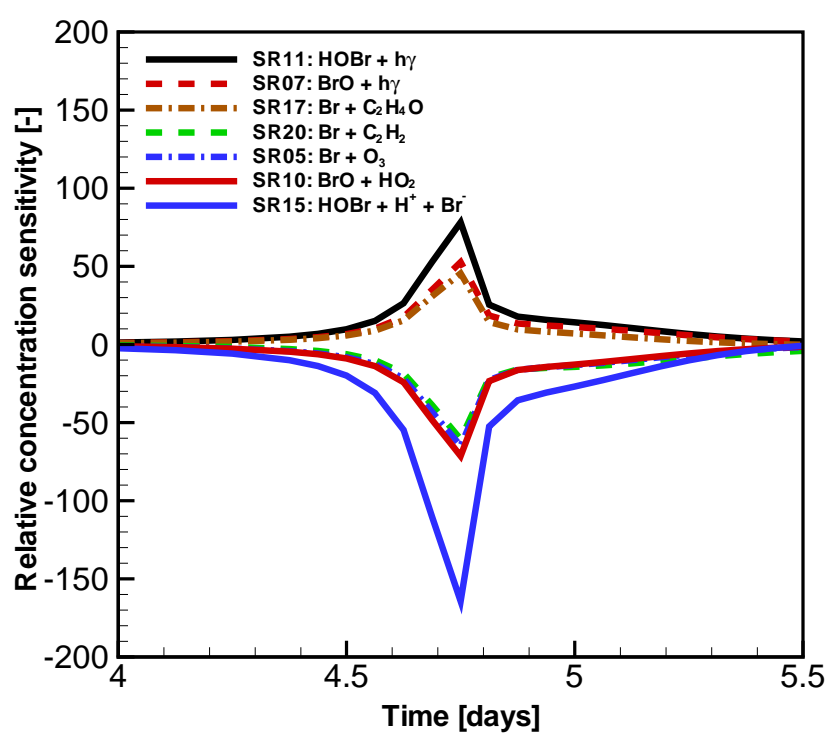

Figure 3. Temporal change of the relative concentration sensitivities of ozone for the dominant reactions between day 4 and day 5.5. Here only the reactions with a maximum absolute value of the relative concentration sensitivities larger than 40 are identified as dominant and shown.

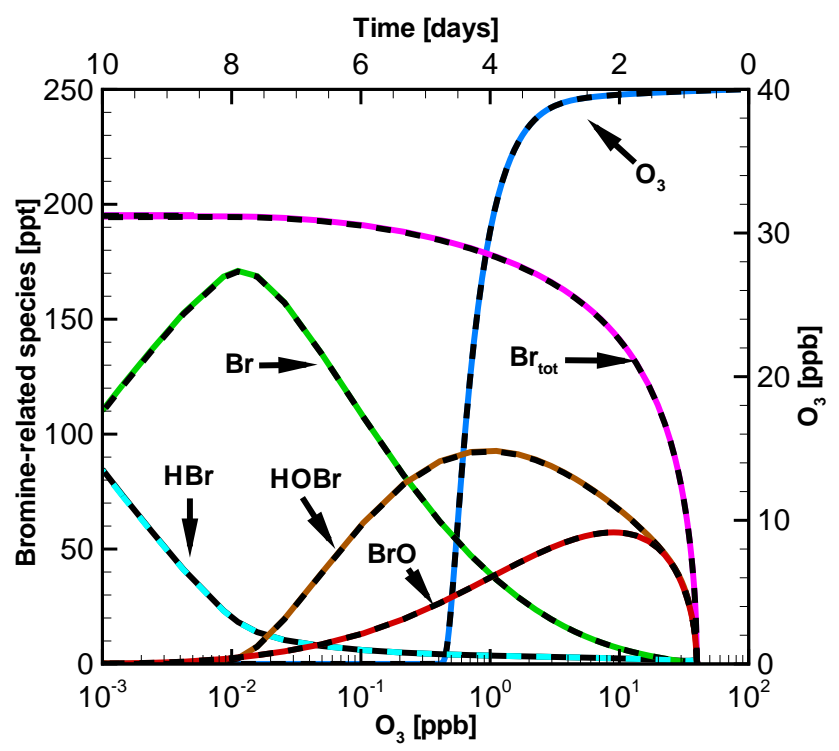

Figure 4. Change of ozone and principal bromine-containing compounds plotted with an ozone coordinate axis and a time coordinate axis. The solid curves denote the simulation results obtained by using the original reaction mechanism, and the dashed curves represent the results for the reduced reaction mechanism, which is obtained after the concentration sensitivity analysis. The curves of ozone mixing ratios use the axis of time while the principal bromine species correspond to the ozone coordinate axis. Note that the axis of time is in a reverse direction for clarity. cipal bromine species from these two mechanisms agree very well, within deviations of $1 \%$.

The principal component analysis was then performed on the sensitivity matrix $\widetilde{\boldsymbol{S}}^{\mathrm{T}} \widetilde{\boldsymbol{S}}$ of the original reaction scheme to simplify the mechanism, which is shown in the next subsection.

\subsection{Principal component analysis of the reaction mechanism of the ODE}

After obtaining the concentration sensitivities of the original reaction mechanism of the ODE, the matrix $\widetilde{\boldsymbol{S}}^{\mathrm{T}} \widetilde{\boldsymbol{S}}$ is constructed and applied in the principal component analysis. The obtained eigenvalues and the corresponding principal components of $\widetilde{\boldsymbol{S}}^{\mathrm{T}} \widetilde{\boldsymbol{S}}$ are listed in Table 4 . The selection criterion $\lambda_{i}<0.3572$ is adopted for removing reactions from the scheme, which has been discussed above. Moreover, in the principal components with large eigenvalues, if an element contributes less than 0.2 to the corresponding principal component, the reaction associated with this element can be also removed. Thus, by summarizing all the reactions, which are identified as redundant according to the principal component analysis, 20 reactions, Reactions (SR2), (SR18), (SR27), (SR28), (SR30), (SR38), (SR40), (SR43), (SR49), (SR52), (SR56), (SR67), (SR71), (SR72), (SR73), (SR74), (SR77), (SR79), (SR80), and (SR87), can be removed from the original reaction scheme, which are indicated in Table 3 by the reaction numbers in bold.

It is found that the reactions identified as unimportant by using the sensitivity analysis are all covered by the principal component analysis. Moreover, nine extra reactions to be eliminated from the reaction scheme are also revealed by the principal component analysis. The reason for the difference between these two approaches is possibly that in a complex reaction mechanism, usually the removal of one single reaction would cause significant variations in the temporal change of many chemical species while the elimination of a group of reactions may have only a minor impact on the response of the system. In the concentration sensitivity analysis, the association between a particular species concentration and each reaction rate is clarified, which is suitable for screening reactions separately. In contrast to that, the principal component analysis is able to identify the dependence of the species concentrations on a group of reactions. Therefore, by performing the principal component analysis, we were able to remove more reactions from the original reaction mechanism. Finally, the reduced reaction mechanism after the implementation of the principal component analysis consists of 39 species and 72 reactions (see Table 3 ).

After performing the principal component analysis, the reduced reaction mechanism was introduced into the box model to simulate the mixing ratio change of ozone and principal bromine species (see Fig. 5). It is seen that the results obtained by using the reduced reaction mechanism agree rea- 
Table 4. Eigenvalues $(\lambda)$ and the corresponding principal components of $\widetilde{\boldsymbol{S}}^{\mathrm{T}} \widetilde{\boldsymbol{S}}$ for the original reaction mechanism of the ODE. The first number in the column of $\lambda$ refers to the number of the eigenvalue, and the value after the hyphen gives the value of $\lambda$. Here only the principal components with eigenvalues larger than 0.3572 are listed. Within each principal component, elements larger than 0.2 are displayed.

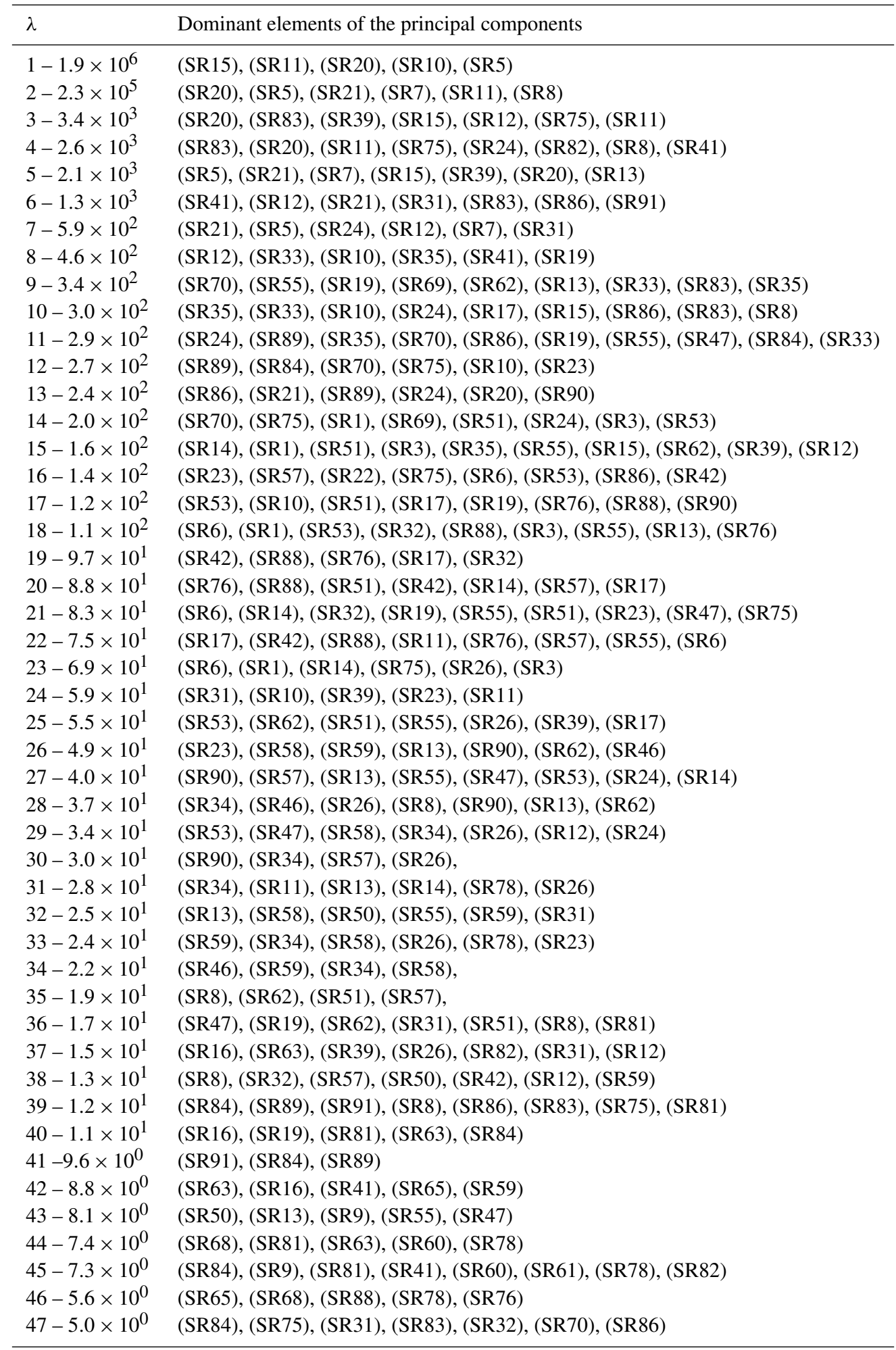


Table 4. Continued.

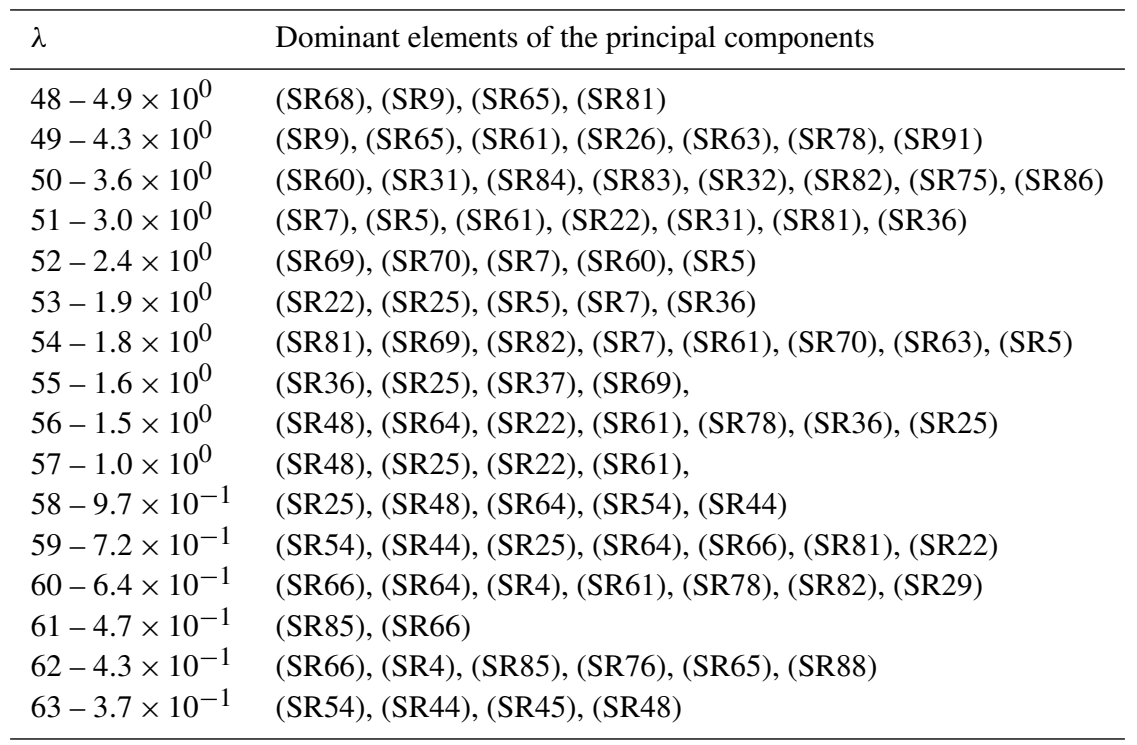

sonably well with those simulated by using the original reaction mechanism. The depletion stage in simulation results using the reduced reaction mechanism starts on day 2.9 and finishes on day 4.4, which occurs a little bit earlier than that using the original reaction mechanism. The maximum deviations of $\mathrm{Br}, \mathrm{HBr}, \mathrm{HOBr}, \mathrm{BrO}$, and $\mathrm{Br}_{\text {tot }}$ are 6.6, 1.6, 8.9, 2.5, and $5.2 \%$, respectively. Thus, the variations in the mixing ratios of the principal bromine species considered in the model caused by the removal of 20 redundant reactions are less than $10 \%$, which is restrained by the selection criterion adopted. Therefore, the reduced reaction mechanism can satisfactorily capture the temporal change of each chemical species so that the requirement of the accuracy of the reaction mechanism is fulfilled for multi-dimensional computations of ODEs.

The principal component analysis was also applied to different time periods of ODEs (induction stage, depletion stage and end stage), and the computational results are displayed in Fig. 6. The yellow contours denote the important reactions in this time period while the black contours show the reactions that can be removed. Similarly, we summarize all the important reactions at different time stages and remove the least significant reactions. It is found that 20 reactions, Reactions (SR2), (SR18), (SR27), (SR28), (SR29), (SR30), (SR38), (SR40), (SR43), (SR45), (SR49), (SR52), (SR56), (SR67), (SR71), (SR73), (SR74), (SR77), (SR79), and (SR80), can be removed according to the principal component analysis for different time periods. It should be noticed that Reactions (SR29) and (SR45), which are identified as important in the global principal component analysis, are currently indicated as redundant. It is because of that although Reactions (SR29) and (SR45) play minor roles and the removal of them causes less than $10 \%$ of the variation in the system response within each time period, from a global

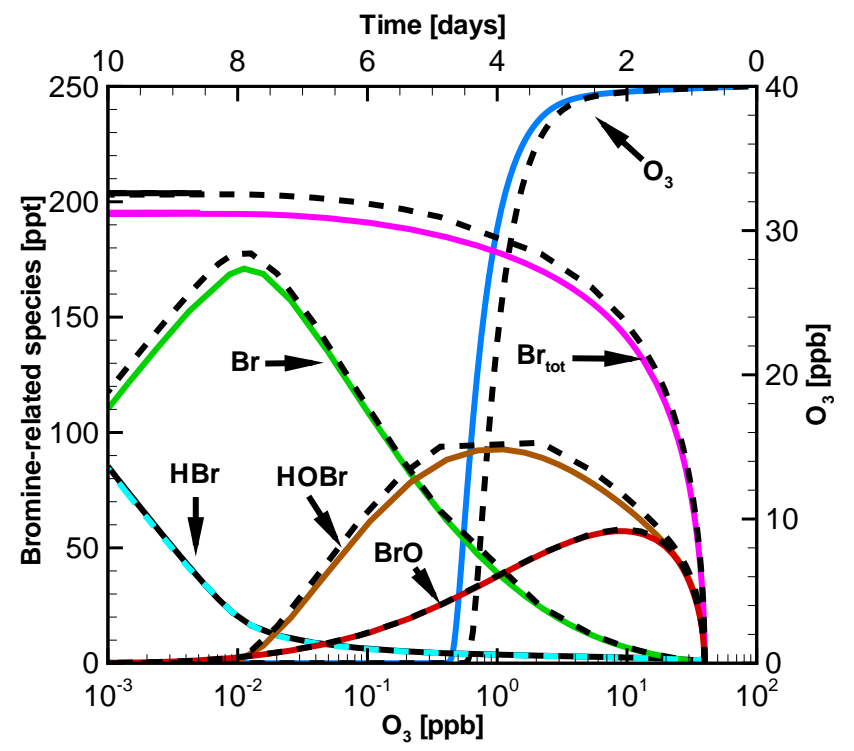

Figure 5. Change of ozone and principal bromine-containing compounds plotted with an ozone coordinate axis and a time coordinate axis. The solid curves denote the simulation results obtained by using the original reaction mechanism, and the dashed curves represent the results for the reduced reaction mechanism, which is obtained after the principal component analysis. The configuration of this figure is similar to that used in Fig. 4.

view of the complete ODE, the variations within each time period would accumulate, which leads to a total concentration change exceeding $10 \%$ of the original value. Therefore, Reactions (SR29) and (SR45) cannot be removed if the selection criterion is strictly obeyed in the global principal component analysis. 
(a)

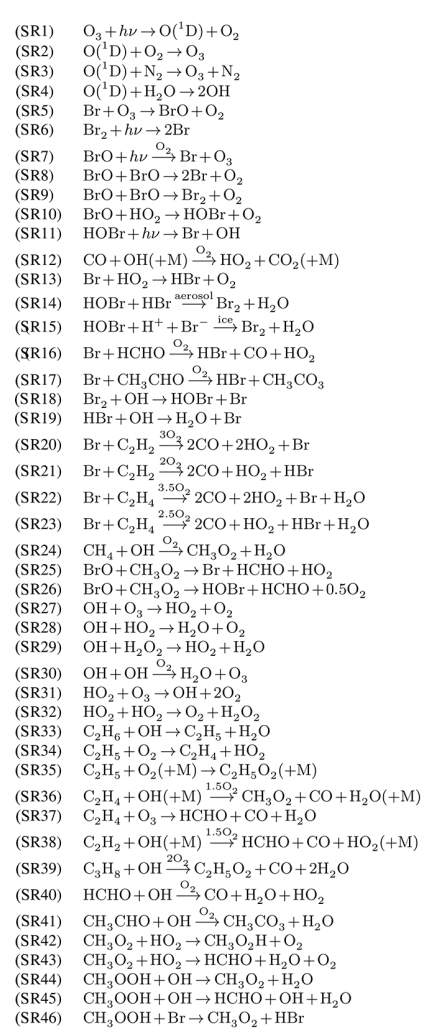

\section{Important}

Negligible

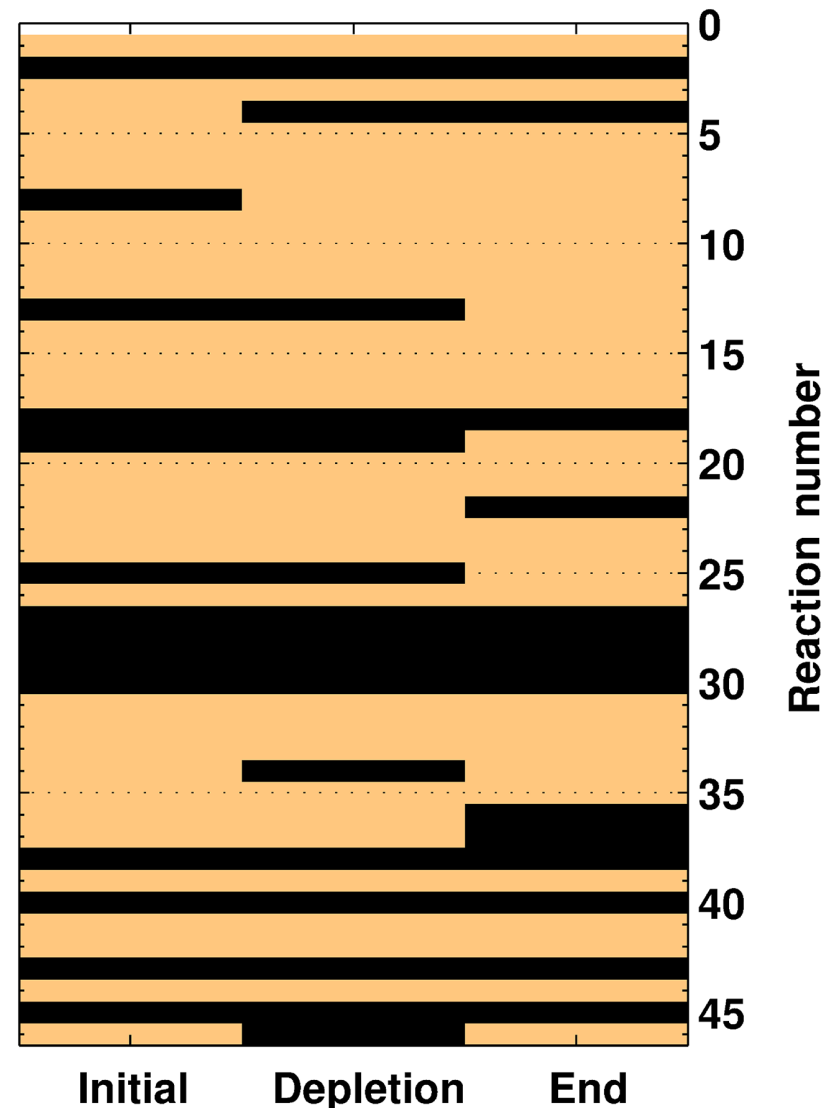

Figure 6.

Moreover, it is also found that Reactions (SR72) and (SR87), which used to be identified as unimportant, are now considered as important, and cannot be removed from the reaction scheme. From the computational results of the principal component analysis for different time periods (see Fig. 6b), it is observed that Reactions (SR72) and (SR87) are all identified as important in the induction stage while their significance during the depletion stage and the end stage are negligible. Thus, in the principal component analysis when the whole depletion event is observed, the importance of Reactions (SR72) and (SR87) are smoothed out. As a result, these two reactions can be removed from the original reaction scheme.

Apart from screening reactions from a complex reaction mechanism, principal component analysis is also capable to clarify the chemical species in quasi-steady state which are indicated by principal components with small eigenvalues. In order to perform this investigation, the principal component analysis was once more applied on the reduced reaction mechanism with 39 species and 72 reactions. By observing the principal components with small eigenvalues (not shown here), we found that no. 71 principal component, which corresponds to the second least eigenvalue, has only two dominant elements, Reaction (SR1): $\mathrm{O}_{3}+h v \rightarrow \mathrm{O}\left({ }^{1} \mathrm{D}\right)+\mathrm{O}_{2}$ and Reactions (SR3): $\mathrm{O}\left({ }^{1} \mathrm{D}\right)+\mathrm{N}_{2} \stackrel{\mathrm{O}_{2}}{\longrightarrow} \mathrm{O}_{3}+\mathrm{N}_{2}$. Besides, the value of the element (SR1), 0.710, is approximately equal to that of Reaction (SR3), 0.704. We also noticed that Reactions (SR1) and (SR3) are the reactions in which the chemical species $\mathrm{O}^{1}(\mathrm{D})$ participates. Thus, it represents that $\mathrm{O}^{1}(\mathrm{D})$ is in quasi-steady state, and the computational results depend only on the ratio of the reaction rates of Reactions (SR1) and (SR3), which can be expressed as

$k_{s}=\frac{k_{1}}{k_{3}}$.

Herein, $k_{1}$ and $k_{3}$ are the rate constants of Reactions (SR1) and (SR3), respectively. In order to confirm this finding, we multiplied the rate coefficient of both Reactions (SR1) and (SR3) by 100 , the deviations of the system after this change are shown in Table 5. It is found that the peak values of the 
(b)

\section{Important}

Negligible
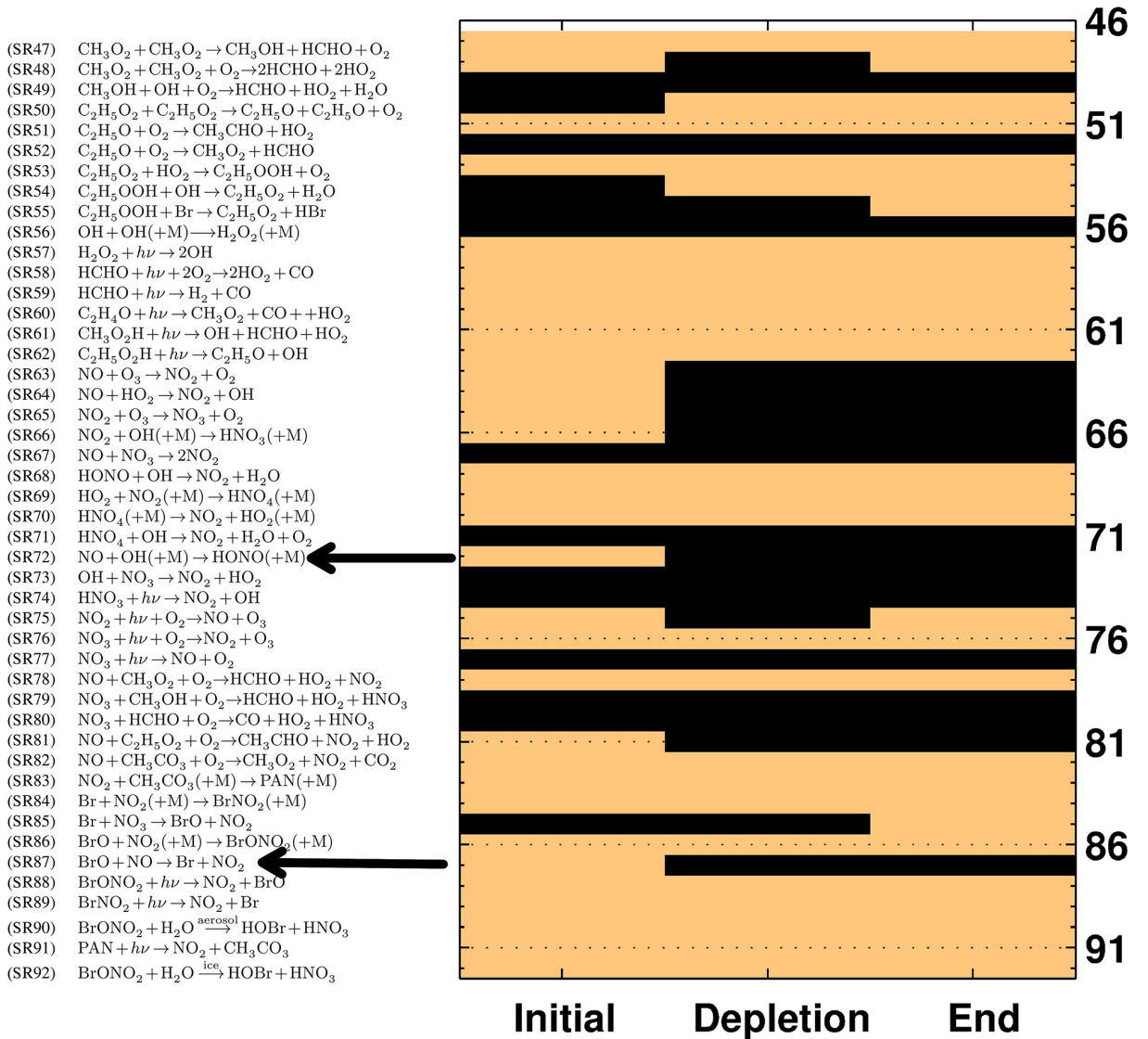

Figure 6. The importance of each reaction in the original reaction mechanism within different time periods, for (a) Reactions (SR1)-(SR46) and (b) Reactions (SR47)-(SR92). Yellow contour denotes that this reaction is important through this time period, while black contour represents that this reaction is identified as insignificant during this time stage.

principal bromine species calculated from the reduced reaction mechanism and from the reaction scheme with the modified reaction rates agree well within $1 \%$. In contrast to that, if we only increase the rate constant of Reaction (SR1) to 100 times of its original value while the rate constant of Reaction (SR3) remains the same, the difference between the results from the original mechanism and the modified mechanism becomes larger (see Table 5). The maximum deviation amounts to $172 \%$ for the species HOBr. This finding also confirms the validity of the principal component analysis.

As $\mathrm{O}^{1}(\mathrm{D})$ was found in quasi-steady state during ODEs, it is possible to directly estimate the mixing ratio of $\mathrm{O}^{1}(\mathrm{D})$ at each time instance according to the mixing ratios of other chemical species. It can be easily deduced that the mixing ratio of $\mathrm{O}^{1}(\mathrm{D})$ during the depletion event can be expressed as

$\left[\mathrm{O}^{1}(\mathrm{D})\right]=\frac{k_{1}\left[\mathrm{O}_{3}\right]}{k_{3}\left[\mathrm{~N}_{2}\right]}$
Table 5. Comparison of the peak values of principal bromine species calculated by using various chemical reaction mechanisms. The peak values shown in the table are calculated by using the reduced reaction mechanism derived after the principal component analysis.

\begin{tabular}{lrrr}
\hline Species & $\begin{array}{r}\text { Peak value } \\
\text { [ppt] }\end{array}$ & $\begin{array}{r}k_{1} \times 100, k_{3} \times 100 \\
\text { deviation [\%] }\end{array}$ & $\begin{array}{r}k_{1} \times 100, k_{3} \times 1 \\
\text { deviation [\%] }\end{array}$ \\
\hline $\mathrm{Br}$ & 177.6 & 0.3 & 104.4 \\
$\mathrm{HBr}$ & 203.7 & 0.1 & 126.8 \\
$\mathrm{HOBr}$ & 95.6 & 0.7 & 172.0 \\
$\mathrm{BrO}$ & 58.1 & 0.1 & 63.7 \\
$\mathrm{Br}_{\text {tot }}$ & 203.8 & 0.1 & 126.7 \\
\hline
\end{tabular}

in which $\left[\mathrm{O}_{3}\right]$ and $\left[\mathrm{N}_{2}\right]$ are the mixing ratios of ozone and nitrogen, respectively. Thus, in multi-dimensional model studies of ODEs, aside from using a reduced reaction mechanism 
to shorten the time cost for the calculation of the chemical source terms, the species equation corresponding to $\mathrm{O}^{1}(\mathrm{D})$ can be also simplified, which improves the efficiency of the computations. However, the simplification of the reaction mechanism by using the quasi-steady-state approximation is beyond the scope of the present study.

\section{Conclusions and future developments}

In the present study, two reduction approaches, namely, the concentration sensitivity analysis and the principal component analysis, were applied on a reaction mechanism representing the chemistry of ODEs. The former was performed based on the ratio of the relative change of species concentrations and the variation of a particular reaction rate. The significance of each reaction in the original mechanism for various chemical species was identified. It was found that during the depletion of ozone, reactions associated with $\mathrm{HOBr}$ are the most influential reactions as they determine the total bromine loading in the atmosphere within this time period. By removing 11 reactions, which exhibit peak absolute values of the sensitivity coefficients lower than $10 \%$, a reduced reaction mechanism of ODEs was derived. The difference between the results obtained by using the original reaction mechanism and the reduced reaction mechanism is negligible, which validates the sensitivity analysis.

The principal component analysis, on the other hand, is able to extract inherent information from a chemical kinetic system via the eigenvalue decomposition of the matrix $\widetilde{\boldsymbol{S}} \widetilde{\boldsymbol{S}}$. In the herein presented study, the reactions that have principal components with eigenvalues lower than a critical criterion were eliminated from the original reaction mechanism. Additionally, the elements that occupy less than 0.2 of each principal component were also removed. In total, 20 reactions were identified as redundant using the principal component analysis and, thus, screened out from the original ODE mechanism. As a result, a reaction scheme with a reduced size consisting of 39 species and 72 reactions was obtained. The deviations of the mixing ratios of ozone and principal bromine species between the original reaction mechanism and the reduced reaction mechanism after the principal component analysis are within $10 \%$. This proves the suitability of the obtained reduced reaction mechanism for multidimensional simulations of ODEs. Apart from this, displayed by the principal components with the smallest eigenvalues, the chemical species $\mathrm{O}^{1}(\mathrm{D})$ is identified to be in quasi-steady state. This facilitates a further improvement of the numerical efficiency in high-dimensional simulations of ODEs.

It should be noted that the horizontal advection, which makes a contribution to the occurrence and termination of ODEs, cannot be captured by the present box model due to the inherent limitations of the 0-D model. In earlier studies, by investigating the origin of the ozone-depleted air at three observational sites in the springtime Arctic, Botten- heim and Chan (2006) revealed that the occurrence of ODEs is linked to a several-day horizontal transport of the cold, ozone-depleted air across the Arctic Ocean covered with fresh sea ice. Their conclusion is also supported by the statistical analysis performed by Hirdman et al. (2009). Moreover, Toyota et al. (2011) found in their 3-D model study that the termination of ODEs during the Arctic spring is associated with enhanced boundary-layer wind transported from the south, carrying the ozone-rich air to the location under observation. However, by showing the dependency of the hourly mean ozone level on the wind speed at Barrow, Alaska, during the springtime of 2009, Helmig et al. (2012) suggested that ODEs are more frequently observed under a calm-wind condition (wind speed $<5 \mathrm{~m} \mathrm{~s}^{-1}$ ). Thus, the relative importance of the horizontal advection for ODEs is still under debate. In order to clarify this, a fully coupled 3-D model is needed, which is beyond the scope of the present box model study. For a future development of the model used in this study, the advection process can be parameterized as a reaction sequence in the mechanism. After this parameterization, it is possible to implement the simplification approaches presented in this study on the reaction mechanism with the inclusion of the horizontal advection.

It is obvious that the applications of the concentration sensitivity analysis and the principal component analysis are not restricted to the reaction mechanism of ODEs, which is the scope of the present study. Any chemical kinetic system, which is expressible through a form of Eq. (1), can be analyzed and optimized by using these two approaches. Furthermore, the readers might have noticed that the two reduction approaches used in the present study do not lead to the removal of species from the detailed reaction mechanism. The reason is that they, rather than employing erroneous simplifications (Vajda et al., 1985; Turányi, 1990b), focus on all occurring chemical species. This, however, prohibits the identification of redundant species. In our present box model, it is found that after the removal of the 11 redundant reactions indicated in the concentration sensitivity analysis, compared with the simulation with the implementation of the original reaction mechanism, the computing time decreases by $10 \%$. In contrast, the use of the reduced reaction mechanism (39 species and 72 reactions) obtained after the principal component analysis causes an $18 \%$ drop of the computing time in our box model. For a further improvement of the simulation efficiency, it seems worthwhile to utilize another approach, which is able to eliminate the redundant species from the reaction mechanism. At present, three types of reduction methods are normally used in previous studies (Turányi and Tomlin, 2014): species lumping, timescaleseparation method, and tabulation approaches. As discussed above, the quasi-steady-state approximation, which belongs to the category of the timescale-separation method, is capable of determining the concentrations of the species in quasisteady state through a function of other species concentrations, which helps to remove the species in quasi-steady state 
from the kinetic reaction scheme. Apart from this, currently, another type of a timescale-based analysis approach, the intrinsic low-dimensional manifolds (ILDM) (Maas and Pope, 1992), is being implemented by the authors of this paper. By means of the ILDM, the dimension of the composition space can be reduced significantly based on the number of the freedom degrees. As a result, the computational effort of the chemical source terms in the rate equations is decreased remarkably, which may further progress the current work.

\section{Data availability}

The output data of the model for the sensitivity analysis and the principal component analysis are available upon request to the contact author Le Cao (le.cao@ nuist.edu.cn).

\section{The Supplement related to this article is available online at doi:10.5194/acp-16-14853-2016-supplement.}

Acknowledgements. The authors are sincerely thankful for the financial supports provided by the National Natural Science Foundation of China (no. 41375044), the Natural Science Foundation of Jiangsu Province (no. 2015s042), the Double Innovation Talent Program (no. R2015SCB02), the Polar Strategic Foundation (no. 20150308), and the Startup Foundation for Introducing Talent of NUIST (no. 2014r066). We also like to thank two anonymous reviewers and the editor Marc von Hobe for their perspicacious comments that significantly improved our work.

Edited by: M. von Hobe

Reviewed by: two anonymous referees

\section{References}

Abbatt, J. P. D., Thomas, J. L., Abrahamsson, K., Boxe, C., Granfors, A., Jones, A. E., King, M. D., Saiz-Lopez, A., Shepson, P. B., Sodeau, J., Toohey, D. W., Toubin, C., von Glasow, R., Wren, S. N., and Yang, X.: Halogen activation via interactions with environmental ice and snow in the polar lower troposphere and other regions, Atmos. Chem. Phys., 12, 6237-6271, doi:10.5194/acp-12-6237-2012, 2012.

Atkinson, R., Baulch, D. L., Cox, R. A., Crowley, J. N., Hampson, R. F., Hynes, R. G., Jenkin, M. E., Kerr, J. A., Rossi, M., and Troe, J.: Summary of evaluated kinetic and photochemical data for atmospheric chemistry, IUPAC Subcommittee on Gas Kinetic Data Evaluation for Atmospheric Chemistry, Cambridge, UK, available at: http://www.iupac-kinetic.ch.cam.ac.uk/ (last access: 26 November 2016), 2006.

Bard, Y.: Nonlinear parameter estimation, Academic Press, New York, 1974.

Barrie, L. A., Bottenheim, J. W., Schnell, R. C., Crutzen, P. J., and Rasmussen, R. A.: Ozone destruction and photochemical reactions at polar sunrise in the lower Arctic atmosphere, Nature, 334, 138-141, doi:10.1038/334138a0, 1988.
Beare, R., Macvean, M., Holtslag, A., Cuxart, J., Esau, I., Golaz, J.-C., Jimenez, M., Khairoutdinov, M., Kosovic, B., Lewellen, D., Lund, T., Lundquist, J., Mccabe, A., Moene, A., Noh, Y., Raasch, S., and Sullivan, P.: An intercomparison of large-eddy simulations of the stable boundary layer, Bound.-Lay. Meteorol., 118, 247-272, doi:10.1007/s10546-004-2820-6, 2006.

Bott, A.: A numerical model of the cloud-topped planetary boundary-layer: Impact of aerosol particles on the radiative forcing of stratiform clouds, Q. J. Roy. Meteor. Soc., 123, 631-656, doi:10.1002/qj.49712353906, 1997.

Bott, A.: A flux method for the numerical solution of the stochastic collection equation: extension to two-dimensional particle distributions, J. Atmos. Sci., 57, 284-294, doi:10.1175/15200469(2000)057<0284:AFMFTN>2.0.CO;2, 2000.

Bott, A., Trautmann, T., and Zdunkowski, W.: A numerical model of the cloud-topped planetary boundary-layer: Radiation, turbulence and spectral microphysics in marine stratus, Q. J. Roy. Meteor. Soc., 122, 635-667, doi:10.1002/qj.49712253105, 1996.

Bottenheim, J., Gallant, A., and Brice, K.: Measurements of $\mathrm{NO}_{y}$ species and $\mathrm{O}_{3}$ at $82^{\circ} \mathrm{N}$ latitude, Geophys. Res. Lett., 13, 113116, doi:10.1029/GL013i002p00113, 1986.

Bottenheim, J. W. and Chan, E.: A trajectory study into the origin of spring time Arctic boundary layer ozone depletion, J. Geophys. Res.-Atmos., 111, D19301, doi:10.1029/2006JD007055, 2006.

Cao, L. and Gutheil, E.: Numerical simulation of tropospheric ozone depletion in the polar spring, Air Qual. Atmos. Health, 6, 673-686, doi:10.1007/s11869-013-0208-9, 2013.

Cao, L., Sihler, H., Platt, U., and Gutheil, E.: Numerical analysis of the chemical kinetic mechanisms of ozone depletion and halogen release in the polar troposphere, Atmos. Chem. Phys., 14, 37713787, doi:10.5194/acp-14-3771-2014, 2014.

Cao, L., He, M., Jiang, H., Grosshans, H., and Cao, N.: Sensitivity of the reaction mechanism of the ozone depletion events during the Arctic spring on the initial atmospheric composition of the troposphere, Atmosphere, 7, 124, doi:10.3390/atmos7100124, 2016 .

Cao, L., Platt, U., and Gutheil, E.: Role of the boundary layer in the occurrence and termination of the tropospheric ozone depletion events in polar spring, Atmos. Environ., 132, 98-110, doi:10.1016/j.atmosenv.2016.02.034, 2016b.

Cao, L., Platt, U., Wang, C., Cao, N., and Qin, Q.: Numerical Analysis of the Role of Snowpack in the Ozone Depletion Events during the Arctic Spring, Atmos. Chem. Phys. Discuss., doi:10.5194/acp-2016-553, in review, 2016c.

Chance, K.: Analysis of BrO measurements from the Global Ozone Monitoring Experiment, Geophys. Res. Lett., 25, 3335-3338, doi:10.1029/98GL52359, 1998.

Dodge, M. and Hecht, T.: Rate constant measurements needed to improve a general kinetic mechanism for photochemical smog, Int. J. Chem. Kinet., 7, 155-163, 1975.

Dougherty, E. P. and Rabitz, H.: Computational kinetics and sensitivity analysis of hydrogen-oxygen combustion, J. Chem. Phys., 72, 6571-6586, 1980.

Edelson, D. and Allara, D. L.: A computational analysis of the alkane pyrolysis mechanism: Sensitivity analysis of individual reaction steps, Int. J. Chem. Kinet., 12, 605-621, doi:10.1002/kin.550120903, 1980. 
Fan, S.-M. and Jacob, D. J.: Surface ozone depletion in Arctic spring sustained by bromine reactions on aerosols, Nature, 359, 522-524, doi:10.1038/359522a0, 1992.

Frieß, U., Hollwedel, J., König-Langlo, G., Wagner, T., and Platt, U.: Dynamics and chemistry of tropospheric bromine explosion events in the Antarctic coastal region, J. Geophys. Res.-Atmos., 109, D06305, doi:10.1029/2003JD004133, 2004.

Glarborg, P., Miller, J. A., and Kee, R. J.: Kinetic modeling and sensitivity analysis of nitrogen oxide formation in well-stirred reactors, Combust. Flame, 65, 177-202, doi:10.1016/00102180(86)90018-0, 1986

Grannas, A. M., Jones, A. E., Dibb, J., Ammann, M., Anastasio, C., Beine, H. J., Bergin, M., Bottenheim, J., Boxe, C. S., Carver, G., Chen, G., Crawford, J. H., Dominé, F., Frey, M. M., Guzmán, M. I., Heard, D. E., Helmig, D., Hoffmann, M. R., Honrath, R. E., Huey, L. G., Hutterli, M., Jacobi, H. W., Klán, P., Lefer, B., McConnell, J., Plane, J., Sander, R., Savarino, J., Shepson, P. B., Simpson, W. R., Sodeau, J. R., von Glasow, R., Weller, R., Wolff, E. W., and Zhu, T.: An overview of snow photochemistry: evidence, mechanisms and impacts, Atmos. Chem. Phys., 7, 43294373, doi:10.5194/acp-7-4329-2007, 2007.

Halfacre, J. W., Knepp, T. N., Shepson, P. B., Thompson, C. R., Pratt, K. A., Li, B., Peterson, P. K., Walsh, S. J., Simpson, W. R., Matrai, P. A., Bottenheim, J. W., Netcheva, S., Perovich, D. K., and Richter, A.: Temporal and spatial characteristics of ozone depletion events from measurements in the Arctic, Atmos. Chem. Phys., 14, 4875-4894, doi:10.5194/acp-14-4875-2014, 2014.

Hanson, D. R., Ravishankara, A. R., and Solomon, S.: Heterogeneous reactions in sulfuric acid aerosols: A framework for model calculations, J. Geophys. Res.-Atmos., 99, 3615-3629, doi:10.1029/93JD02932, 1994.

Hausmann, M. and Platt, U.: Spectroscopic measurement of bromine oxide and ozone in the high Arctic during Polar Sunrise Experiment 1992, J. Geophys. Res.-Atmos., 99, 25399-25413, doi:10.1029/94JD01314, 1994.

Helmig, D., Oltmans, S. J., Carlson, D., Lamarque, J.-F., Jones, A., Labuschagne, C., Anlauf, K., and Hayden, K.: A review of surface ozone in the polar regions, Atmos. Environ., 41, 5138-5161, doi:10.1016/j.atmosenv.2006.09.053, 2007.

Helmig, D., Boylan, P., Johnson, B., Oltmans, S., Fairall, C., Staebler, R., Weinheimer, A., Orlando, J., Knapp, D. J., Montzka, D. D., Flocke, F., Frieß, U., Sihler, H., and Shepson, P. B.: Ozone dynamics and snow-atmosphere exchanges during ozone depletion events at Barrow, Alaska, J. Geophys. Res.-Atmos., 117, D20303, doi:10.1029/2012JD017531, 2012.

Hirdman, D., Aspmo, K., Burkhart, J. F., Eckhardt, S., Sodemann, H., and Stohl, A.: Transport of mercury in the Arctic atmosphere: Evidence for a spring-time net sink and summer-time source, Geophys. Res. Lett., 36, 267-272, 2009.

Jacobi, H.-W., Frey, M. M., Hutterli, M. A., Bales, R. C., Schrems, O., Cullen, N. J., Steffen, K., and Koehler, C.: Measurements of hydrogen peroxide and formaldehyde exchange between the atmosphere and surface snow at Summit, Greenland, Atmos. Environ., 36, 2619-2628, doi:10.1016/S1352-2310(02)00106-1, 2002.

Jones, A. E., Weller, R., Wolff, E. W., and Jacobi, H. W.: Speciation and rate of photochemical $\mathrm{NO}$ and $\mathrm{NO}_{2}$ production in Antarctic snow, Geophys. Res. Lett., 27, 345-348, doi:10.1029/1999GL010885, 2000.
Jones, A. E., Weller, R., Anderson, P. S., Jacobi, H.-W., Wolff, E. W., Schrems, O., and Miller, H.: Measurements of $\mathrm{NO}_{x}$ emissions from the Antarctic snowpack, Geophys. Res. Lett., 28, 1499-1502, doi:10.1029/2000GL011956, 2001.

Jones, A. E., Anderson, P. S., Wolff, E. W., Turner, J., Rankin, A. M., and Colwell, S. R.: A role for newly forming sea ice in springtime polar tropospheric ozone loss? Observational evidence from Halley station, Antarctica, J. Geophys. Res.-Atmos., 111, D08306, doi:10.1029/2005JD006566, 2006.

Jones, A. E., Anderson, P. S., Begoin, M., Brough, N., Hutterli, M. A., Marshall, G. J., Richter, A., Roscoe, H. K., and Wolff, E. W.: $\mathrm{BrO}$, blizzards, and drivers of polar tropospheric ozone depletion events, Atmos. Chem. Phys., 9, 4639-4652, doi:10.5194/acp-94639-2009, 2009.

Jones, A. E., Anderson, P. S., Wolff, E. W., Roscoe, H. K., Marshall, G. J., Richter, A., Brough, N., and Colwell, S. R.: Vertical structure of Antarctic tropospheric ozone depletion events: characteristics and broader implications, Atmos. Chem. Phys., 10, 7775-7794, doi:10.5194/acp-10-7775-2010, 2010.

Kreher, K., Johnston, P. V., Wood, S. W., Nardi, B., and Platt, U.: Ground-based measurements of tropospheric and stratospheric $\mathrm{BrO}$ at Arrival Heights, Antarctica, Geophys. Res. Lett., 24, 3021-3024, doi:10.1029/97GL02997, 1997.

Langendörfer, U., Lehrer, E., Wagenbach, D., and Platt, U.: Observation of filterable bromine variabilities during Arctic tropospheric ozone depletion events in high (1 hour) time resolution, J. Atmos. Chem., 34, 39-54, doi:10.1023/A:1006217001008, 1999.

Lehrer, E., Hönninger, G., and Platt, U.: A one dimensional model study of the mechanism of halogen liberation and vertical transport in the polar troposphere, Atmos. Chem. Phys., 4, 24272440, doi:10.5194/acp-4-2427-2004, 2004.

Lifshitz, A. and Frenklach, M.: Mechanism of the high temperature decomposition of propane, J. Phys. Chem., 79, 686-692, doi:10.1021/j100574a004, 1975.

Maas, U. and Pope, S. B.: Simplifying chemical kinetics: Intrinsic low-dimensional manifolds in composition space, Combust. Flame, 88, 239-264, 1992.

McConnell, J. C., Henderson, G. S., Barrie, L., Bottenheim, J., Niki, H., Langford, C. H., and Templeton, E. M. J.: Photochemical bromine production implicated in Arctic boundary-layer ozone depletion, Nature, 355, 150-152, doi:10.1038/355150a0, 1992.

Michalowski, B. A., Francisco, J. S., Li, S.-M., Barrie, L. A., Bottenheim, J. W., and Shepson, P. B.: A computer model study of multiphase chemistry in the Arctic boundary layer during polar sunrise, J. Geophys. Res.-Atmos., 105, 15131-15145, doi:10.1029/2000JD900004, 2000.

Oltmans, S. J.: Surface ozone measurements in clean air, J. Geophys. Res.-Oceans, 86, 1174-1180, doi:10.1029/JC086iC02p01174, 1981.

Pandis, S. N. and Seinfeld, J. H.: Sensitivity analysis of a chemical mechanism for aqueous-phase atmospheric chemistry, J. Geophys. Res.-Atmos., 94, 1105-1126, doi:10.1029/JD094iD01p01105, 1989.

Piot, M. and von Glasow, R.: The potential importance of frost flowers, recycling on snow, and open leads for ozone depletion events, Atmos. Chem. Phys., 8, 2437-2467, doi:10.5194/acp-82437-2008, 2008. 
Piot, M. and von Glasow, R.: Modelling the multiphase near-surface chemistry related to ozone depletions in polar spring, J. Atmos. Chem., 64, 77-105, doi:10.1007/s10874-010-9170-1, 2009.

Platt, U. and Hönninger, G.: The role of halogen species in the troposphere, Chemosphere, 52, 325-338, doi:10.1016/S00456535(03)00216-9, 2003.

Platt, U. and Janssen, C.: Observation and role of the free radicals $\mathrm{NO}_{3}, \mathrm{ClO}, \mathrm{BrO}$ and $\mathrm{IO}$ in the troposphere, Faraday Discuss., 100, 175-198, doi:10.1039/FD9950000175, 1995.

Platt, U. and Lehrer, E.: Arctic tropospheric ozone chemistry, ARCTOC, no. 64 in Air pollution research report, European Commission Directorate-General, Science, Research and Development, Luxembourg, 1997.

Platt, U. and Wagner, T.: Satellite mapping of enhanced $\mathrm{BrO}$ concentrations in the troposphere, Nature, 395, 486-490, doi:10.1038/26723, 1998.

Rabitz, H., Kramer, M., and Dacol, D.: Sensitivity analysis in chemical kinetics, Annu. Rev. Phys. Chem., 34, 419-461, doi:10.1146/annurev.pc.34.100183.002223, 1983.

Richter, A., Wittrock, F., Eisinger, M., and Burrows, J. P.: GOME observations of tropospheric BrO in northern hemispheric spring and summer 1997, Geophys. Res. Lett., 25, $2683-$ 2686, doi:10.1029/98GL52016, 1998.

Röth, E. P.: A fast algorithm to calculate the photonflux in optically dense media for use in photochemical models, Berichte der Bunsengesellschaft für physikalische Chemie, 96, 417-420, doi:10.1002/bbpc.19920960335, 1992.

Röth, E. P.: Description of the anisotropic radiation transfer model ART to dermine photodissociation coefficients, Vol. 3960, Forschungszentrum, Zentralbibliothek, Jülich, 2002.

Saiz-Lopez, A., Plane, J. M. C., Mahajan, A. S., Anderson, P. S., Bauguitte, S. J.-B., Jones, A. E., Roscoe, H. K., Salmon, R. A., Bloss, W. J., Lee, J. D., and Heard, D. E.: On the vertical distribution of boundary layer halogens over coastal Antarctica: implications for $\mathrm{O}_{3}, \mathrm{HO}_{x}, \mathrm{NO}_{x}$ and the $\mathrm{Hg}$ lifetime, Atmos. Chem. Phys., 8, 887-900, doi:10.5194/acp-8-887-2008, 2008.

Sander, R. and Crutzen, P. J.: Model study indicating halogen activation and ozone destruction in polluted air masses transported to the sea, J. Geophys. Res.-Atmos., 101, 9121-9138, doi:10.1029/95JD03793, 1996.

Sander, R. and Morin, S.: Introducing the bromide/alkalinity ratio for a follow-up discussion on "Precipitation of salts in freezing seawater and ozone depletion events: a status report", by Morin et al., published in Atmos. Chem. Phys., 8, 7317-7324, 2008, Atmos. Chem. Phys., 10, 7655-7658, doi:10.5194/acp-10-76552010, 2010.

Sander, R., Vogt, R., Harris, G. W., and Crutzen, P. J.: Modelling the chemistry of ozone, halogen compounds, and hydrocarbons in the arctic troposphere during spring, Tellus B, 49, 522-532, doi:10.1034/j.1600-0889.49.issue5.8.x, 1997.

Sander, R., Kerkweg, A., Jöckel, P., and Lelieveld, J.: Technical note: The new comprehensive atmospheric chemistry module MECCA, Atmos. Chem. Phys., 5, 445-450, doi:10.5194/acp-5445-2005, 2005.

Sander, R., Burrows, J., and Kaleschke, L.: Carbonate precipitation in brine - a potential trigger for tropospheric ozone depletion events, Atmos. Chem. Phys., 6, 4653-4658, doi:10.5194/acp-64653-2006, 2006.
Simpson, W. R., von Glasow, R., Riedel, K., Anderson, P., Ariya, P., Bottenheim, J., Burrows, J., Carpenter, L. J., Frieß, U., Goodsite, M. E., Heard, D., Hutterli, M., Jacobi, H.-W., Kaleschke, L., Neff, B., Plane, J., Platt, U., Richter, A., Roscoe, H., Sander, R., Shepson, P., Sodeau, J., Steffen, A., Wagner, T., and Wolff, E.: Halogens and their role in polar boundary-layer ozone depletion, Atmos. Chem. Phys., 7, 4375-4418, doi:10.5194/acp-74375-2007, 2007.

Stull, R. B.: An introduction to boundary layer meteorology, Kluwer Academic Publishers, the Netherlands, 1988.

Tang, T. and McConnell, J. C.: Autocatalytic release of bromine from Arctic snow pack during polar sunrise, Geophys. Res. Lett., 23, 2633-2636, doi:10.1029/96GL02572, 1996.

Toyota, K., McConnell, J. C., Lupu, A., Neary, L., McLinden, C. A., Richter, A., Kwok, R., Semeniuk, K., Kaminski, J. W., Gong, S.-L., Jarosz, J., Chipperfield, M. P., and Sioris, C. E.: Analysis of reactive bromine production and ozone depletion in the Arctic boundary layer using 3-D simulations with GEM-AQ: inference from synoptic-scale patterns, Atmos. Chem. Phys., 11, 3949-3979, doi:10.5194/acp-11-3949-2011, 2011.

Toyota, K., McConnell, J. C., Staebler, R. M., and Dastoor, A. P.: Air-snowpack exchange of bromine, ozone and mercury in the springtime Arctic simulated by the 1-D model PHANTAS - Part 1: In-snow bromine activation and its impact on ozone, Atmos. Chem. Phys., 14, 4101-4133, doi:10.5194/acp-14-41012014, 2014.

Turányi, T.: KINAL - a program package for kinetic analysis of reaction mechanisms, Comput. Chem., 14, 253-254, 1990a.

Turányi, T.: Sensitivity analysis of complex kinetic systems. Tools and applications, J. Math. Chem., 5, 203-248, doi:10.1007/BF01166355, 1990b.

Turányi, T. and Bérces, T.: Kinetics of reactions occurring in the unpolluted troposphere, II. Sensitivity analysis, React. Kinet. Catal. Lett., 41, 103-108, doi:10.1007/BF02075489, 1990.

Turányi, T. and Tomlin, A. S.: Analysis of kinetic reaction mechanisms, Springer, Berlin Heidelberg, 2014.

Turányi, T., Bérces, T., and Vajda, S.: Reaction rate analysis of complex kinetic systems, Int. J. Chem. Kinet., 21, 83-99, doi:10.1002/kin.550210203, 1989.

Vajda, S. and Turányi, T.: Principal component analysis for reducing the Edelson-Field-Noyes model of the BelousovZhabotinskii reaction, J. Phys. Chem., 90, 1664-1670, doi:10.1021/j100399a042, 1986.

Vajda, S., Valko, P., and Turányi, T.: Principal component analysis of kinetic models, Int. J. Chem. Kinet., 17, 55-81, 1985.

Valko, P. and Vajda, S.: An extended ODE solver for sensitivity calculations, Comput. Chem., 8, 255-271, doi:10.1016/00978485(84)85017-2, 1984.

Wagner, T., Leue, C., Wenig, M., Pfeilsticker, K., and Platt, U.: Spatial and temporal distribution of enhanced boundary layer $\mathrm{BrO}$ concentrations measured by the GOME instrument aboard ERS-2, J. Geophys. Res.-Atmos., 106, 24225-24235, doi:10.1029/2000JD000201, 2001.

Wagner, T., Ibrahim, O., Sinreich, R., Frieß, U., von Glasow, R., and Platt, U.: Enhanced tropospheric BrO over Antarctic sea ice in mid winter observed by MAX-DOAS on board the research vessel Polarstern, Atmos. Chem. Phys., 7, 3129-3142, doi:10.5194/acp-7-3129-2007, 2007. 
Warnatz, H. C. J., Maas, U., and Dibble, R. W.: Combustion physical and chemical fundamentals, modeling and simulation, Springer-Verlag, Berlin Heidelberg, 2001.

Warnatz, J.: Resolution of gas phase and surface combustion chemistry into elementary reactions, Twenty-Fourth Symposium (International) on Combustion, 24, 553-579, doi:10.1016/S00820784(06)80070-6, 1992.

Wennberg, P.: Atmospheric chemistry: Bromine explosion, Nature, 397, 299-301, doi:10.1038/16805, 1999.

Yang, X., Pyle, J. A., Cox, R. A., Theys, N., and Van Roozendael, M.: Snow-sourced bromine and its implications for polar tropospheric ozone, Atmos. Chem. Phys., 10, 7763-7773, doi:10.5194/acp-10-7763-2010, 2010.
Zeng, T., Wang, Y., Chance, K., Browell, E. V., Ridley, B. A., and Atlas, E. L.: Widespread persistent near-surface ozone depletion at northern high latitudes in spring, Geophys. Res. Lett., 30, 2298, doi:10.1029/2003GL018587, 2003.

Zhao, T. L., Gong, S. L., Bottenheim, J. W., McConnell, J. C., Sander, R., Kaleschke, L., Richter, A., Kerkweg, A., Toyota, K., and Barrie, L. A.: A three-dimensional model study on the production of $\mathrm{BrO}$ and Arctic boundary layer ozone depletion, J. Geophys. Res.-Atmos., 113, D24304, doi:10.1029/2008JD010631, 2008. 